\title{
Functional Identification of Central Afferent Projections Conveying Information of Acute "Stress" to the Hypothalamic Paraventricular Nucleus
}

\author{
Philip J. Larsen and Jens D. Mikkelsen \\ Department of Anatomy, The Panum Institute, University of Copenhagen, Copenhagen, Denmark
}

Intraperitoneal administration of hypertonic saline is a potent stimulus to the "stress" responsive hypophysiotrophic parvicellular neurons of the hypothalamic paraventricular nucleus (PVN), as well as to magnocellular neurons of the hypothalamo-neurohypophysial system. Precise identification of the pathways gating information about the "stress" of intraperitoneal hypertonic saline to the PVN has not been ascertained earlier. In this study we demonstrate that intraperitoneal injection of hypertonic saline induces increased expression of $c$-fos immunoreactivity within neurons of the medial parvicellular division of the PVN, within the circumventricular organs surrounding the anteroventral tip of the third ventricle, and within the magnocellular neurons of the PVN and supraoptic nucleus. Also, neurons involved in conveying visceral information to the PVN, including the parabrachial nucleus, the nucleus of the solitary tract and the ventrolateral medulla responded with increased c-fos expression to the "stress" paradigm. Combined $c$-fos immunocytochemistry and retrograde tracing experiments with cholera toxin $B(C h B)$ was used to identify neurons projecting to the PVN activated by the applied "stressor." Neither the mere intracerebral presence of $\mathrm{ChB}$ nor intraperitoneal administration of isotonic saline influenced the number of $c$-fos immunoreactive nuclei in the brain. Dual immunocytochemistry revealed that intraperitoneal administration of hypertonic saline induced expression of $c$-fos immunoreactive nuclei in approximately half of the retrogradely labeled neurons projecting to the PVN from the anteroventral tip of the third ventricle (AV3v), including the subfornical organ (SFO) and the organum vasculosum laminae terminalis (OVLT). In the brainstem, the "stressor" induced expression of $c$-fos-IR nuclei in almost all of the retrogradely labeled cells of the ventrolateral part of the medulla oblongata (A1 and $\mathrm{C1}$ ), while only about $25 \%$ of the ChB-labeled cells of the caudal part of the nucleus of the solitary tract (A2) were concomitantly immunoreactive to $c$-fos. Within the parabrachial nucleus,

Received July 6, 1994; revised Oct. 25, 1994; accepted Oct. 31, 1994.

The technical help of Miss Gitte G. Sørensen and Tine Gerlén is greatly appreciated. We thank Drs. Evans and Hancock (London, U.K.) for their kind donation of rabbit $c$-fos antiserum. This study was supported by The Danish Medical Research Council (12-1642-1); The Danish Government Biotechnology Center for Signal Peptide Research, Danish Heart Foundation; Danish Diabetes Foundation; NOVO's Foundation; NOVO-Nordisk Foundation.

Correspondence should be addressed to Philip Just Larsen, M.D., Ph.D., Department of Anatomy, Section B. The Panum Institute, Blegdamsvej 3, 2200 Copenhagen N, Denmark.

Copyright (C) 1995 Society for Neuroscience $\quad 0270-6474 / 95 / 152609-19 \$ 05.00 / 0$ only $20 \%$ of the ChB-labeled cells were also immunoreactive for c-fos. The present results provide evidence that information about the "stress" of intraperitoneal hypertonic saline is conveyed to both magnocellular neurons projecting to the neurohypophysls and hypophysiotrophic parvicellular neurons the PVN via afferent projections from a variety of neurons in the osmosensitive anteroventral tip of the third ventricle and visceromotor neurons of the parabrachial nucleus, the ventrolateral medulla and the nucleus of the solitary tract.

[Key words: c-fos, corticotropin-releasing factor, neurosecretory neurons, paraventricular nucleus, transcription factors, neuroendocrinology, cholera toxin subunit $B$, retrograde tracing]

The protooncogene c-fos is member of a family of immediate early genes that are expressed in neurons and transiently activated by a variety of stimuli (Greenberg and Ziff, 1984; Hunt et al., 1987; Sagar et al., 1988; Burlitt, 1990; Morgan and Curran, 1991). Upon activation, the phosphoprotein $c$-fos dimerizes with a member of the jun-family of immediate early genes and regulates the expression of yet other genes via binding to an activator protein-binding site. $C$-fos is induced transiently in most neurons in response to synaptic stimulation (for review see Morgan and Curran, 1991), and because only activated neurons express this protein, the anatomical demonstration of rapid $c$-fos expression in response to stimulation offers an excellent way to integrate physiology and behavior. Thus, some stressful stimuli induces an expression of the $c$-fos gene within the hypothalamic constituents of the hypothalamo-hypophysial-adrenocortical (HA)-axis (Ceccatelli et al., 1989; Sharp et al., 1991), and in certain instances the stress-induced increase of corticotrophinreleasing factor (CRF) mRNA expression is preceded by an induction of c-fos mRNA (Imaki et al., 1992) although a direct link between these events awaits to be demonstrated. The hypothalamic structures activated during an acute osmotic challenge can also be visualized using $c$-fos expression as a marker of neuronal excitation (Giovanelli and Bloom, 1992; Guldenaar et al., 1992; Leng et al., 1992). However, a number of stimulation paradigms inducing neuronal depolarizations are not associated with $c$-fos expression emphasizing that the functional anatomical approach of $c$-fos immunocytochemistry is not universally applicable (Sagar et al., 1988; Morgan and Curran, 1991).

The bulk of hypophysiotrophic CRF containing neurons resides in the hypothalamic paraventricular nucleus (PVN) which integrates and orchestrates neuroendocrine and homeostatic 
functions (Swanson and Sawchenko, 1983; Swanson and Sawchenko, 1986; Hatton, 1990). However, the PVN is a complex structure characterized by its content of different types of neurons recognized from both morphological, connectional and functional distinctions (Swanson, 1987). Neurons of the magnocellular subnuclei are via their release of either vasopressin or oxytocin from the neurohypophysis involved in osmoregulation and body fluid homeostasis (for review, see Hatton, 1990), whereas the central neurons of the HA-axis are CRF containing neurons preferentially situated within the dorsal region of the medial parvicellular part of the PVN (Sawchenko et al., 1992; Sawchenko et al., 1984).

During recent years much attention has focused on the role of neuroendocrine neurons of the PVN as central regulators of the endocrine effects observed in response to a wide variety of stressful stimuli. From study performed on animals with hyponatremia-induced inhibition of magnocellular neurons it has been shown that the acute ether "stress" or systemic injections of hypertonic saline activate both the neuroendocrine cells of HA-axis as well as the magnocellular hypothalamo-neurohypophysial neurons (Dohanics et al., 1991). Using the hypertonic saline injection model of acute "stress" it has been shown that levels of transcripts encoding CRF, enkephalin, and vasopressin increase within the PVN (Lightman and Young, 1988; Lightman and Young III, 1989). The expression of CRF mRNA in the PVN is differentially and independently regulated by glucocorticoid feedback and trans-synaptic regulation, with glucocorticoids mediating the overall gain of the system, while trans-synaptic events predominantly mediate moment-to-moment effects (Lightman and Young, 1989).

Magnocellular vasopressin cells are osmoreceptive themselves, but under normal physiological conditions these neurons are to a large extent under the influence of the circumventricular organs of the anteroventral tip of the third ventricle (Av3V) which constantly monitor the extracellular osmotic pressure of the systemic circuit (for review, see Bisset and Chowdrey, 1988; Leng et al., 1989). Lesions of the organum vasculosum laminae terminalis (OVLT) and the median preoptic nucleus, both structures which are enclosed by the Av3V, significantly reduces the ability of magnocellular neurons to secrete vasopressin in response to changes of the osmotic pressure (Leng et al., 1988; Ramsay et al., 1983). This area is also critically involved in the mediation of the increased CRF mRNA synthesis in oxytocinergic magnocellular neurons and the decreased CRF mRNA synthesis in parvicellular neurons of the PVN seen in response to chronic osmotic stimulation (Kovács and Sawchenko, 1993). The pathways mediating the acute effect of a systemic injection of hypertonic saline to the neuroendocrine neurons of both the hypophysiotrophic CRF neurons within the medial parvicellular part of the PVN and the magnocellular neurons are likely toat least partially - involve the ascending catecholaminergic pathways (Cunningham and Sawchenko, 1988; Plotsky et al., 1989; Cunningham et al., 1990). However, lesions of the ventral noradrenergic bundle or the PVN with 6-hydroxydopamine do not affect basal or "stress"-induced levels of CRF transcripts (Harbuz et al., 1991), suggesting that a number of stimulatory inputs converge on the CRF neurons within the PVN. Other inputs which have been ascribed stimulatory to the CRF neurons of the HA-axis originate from serotonergic neurons of the dorsal raphe (Sawchenko et al., 1983; Saphier, 1991), the histaminergic neurons of the tuberomammillary nuclei (Knigge and Warberg,
1991), and from neurons of the pontine parabrachial nucleus (Jhamandas et al., 1992; Kainu et al., 1993).

The present study has used immunocytochemical visualization of $c$-fos antigen to identify neurons in the circumventricular organs and the catecholaminergic brainstem nuclei activated the acute "stress" of an intraperitoneal injection of hypertonic saline. These studies were carried out on rats iontophoretically injected with the retrograde cholera toxin B tracer into the PVN 1 week prior to the application of the stress stimulus. Subsequent dual immunohistochemical visualization of the cholera toxin $B$ tracer and $c$-fos antigen enabled an identification of neurons projecting to the PVN from the rostral circumventricular organs, the catecholaminergic brainstem nuclei and the parabrachial nuclei, which at the same time were activated by an acute osmotic stress.

\section{Materials and Methods}

Animals. Male Wistar rats (150-180 gm) housed under standard laboratory conditions with free access to food and water were used throughout the study. The animals were kept under a $12 \mathrm{hr}: 12 \mathrm{hr}$ light: dark cycle, and all "stress" experiments were performed between zeitgeber time 3 and 5 .

Retrograde tracings. In order to obtain successful iontophoretic injections with cholera toxin subunit B (choleragenoid, ChB, Sigma Chemical (Co., MO) it was necessary to replace the excessive amounts of ions in the original buffer by $0.05 \mathrm{M}$ phosphate buffered saline (PBS, $\mathrm{pH}$ 7.4). Therefore, $\mathrm{ChB}$ was dialyzed through a Spectra/por molecular porous membrane \#3 (Spectrum Medical Industries Inc., Los Angeles, CA) with a molecular weight cut-off at approximately 3500 Da. Each choleragenoid is composed of five subunits (MW 11,000). Two milligram of lyophilized $\mathrm{ChB}$ was reconstituted in $1 \mathrm{ml}$ of distilled $\mathrm{H}_{2} \mathrm{O}$ and then dialyzed against distilled $\mathrm{H}_{2} \mathrm{O}$ for $1 \mathrm{hr}$ at $20^{\circ} \mathrm{C}$. After dialysis the $\mathrm{ChB}$ solution was concentrated by evaporation in a rotating vacuum evaporator to a final volume of $200 \mu \mathrm{l}$. Then the dialyzed $\mathrm{ChB}$ was reconstituted (dilution factor 1:2.5) in $0.05 \mathrm{M}$ PBS ( $\mathrm{pH} 7.4$ ).

Twenty-four adult male Wistar rats were used for retrograde labeling with ChB. The animals were anesthetized with tribromethanol $(20 \mathrm{mg} /$ $100 \mathrm{gm}$ b.w.) and placed in a stereotaxic frame. Glass capillary microelectrodes with a tip diameter of $15-20 \mu \mathrm{m}$ were filled with the $0.4 \%$ solution of dialyzed $\mathrm{ChB}$, and inserted into the PVN as previously described (Larsen et al., 1994). Injection coordinates were in the range of $1.5-1.9 \mathrm{~mm}$ caudal, $0.1-0.5 \mathrm{~mm}$ lateral to bregma, and $7.6-8.1 \mathrm{~mm}$ below dura according to the atlas of (Paxinos and Watson, 1986). The incisor bar was $2.7 \mathrm{~mm}$ below the ear bars. $\mathrm{ChB}$ was injected by applying a pulsatile positive current of $5-10 \mu \mathrm{A}(0.5 \mathrm{sec}$ on, $0.5 \mathrm{sec}$ off $)$ for 5-10 min. The microelectrode was left in situ for an additional 10 min to avoid spread of tracer along the pipette track.

After a survival of $7 \mathrm{~d}$ the animals were exposed to a hyperosmotic "stress" by an intraperitoneal (i.p.) injection of hypertonic saline $(1.5$ $\mathrm{M} ; 0.018 \mathrm{ml} / \mathrm{gm} \mathrm{b}$.w.). Animals receiving a similar volume of isotonic saline intraperitoneal served as controls. Ninety minutes after the osmotic challenge animals were reanesthetized with tribromethanol (20 $\mathrm{mg} / 100 \mathrm{gm} \mathrm{b.w.)}$ and perfused transcardially with heparinized $(15,000$ IU/liter) $0.02 \%$ potassium containing PBS (KPBS), followed by $4 \%$ paraformaldehyde dissolved in $0.1 \mathrm{M}$ phosphate buffer $(\mathrm{pH} 7.4)$ for 15 min at room temperature. The brains were removed and postfixed in the same fixative overnight and cryoprotected in a $20 \%$ sucrose-KPBS solution for $2 \mathrm{~d}$. One-in-six series of $40 \mu \mathrm{m}$ thick frontal sections were cut in a cryostat and collected in KPBS. The time span between stimulus application and perfusion was selected for analysis on the basis of previous studies of $c$-fos immunoreactivity following intraperitoneal hy pertonic saline injections which showed maximal intensity of the immunoreactive products in both magnocellular and parvicellular neurons of the PVN at 60-120 min after application of the stimulus (Sagar et al., 1988; Sharp et al., 1991). A number of control groups was included in the analysis. Firstly, to assess whether the mere presence of the tracer had any effect upon $c$-fos expression, a group of naive nonhandled animals served as a control for animals receiving the $\mathrm{ChB}$ tracer but not being subjected to the intraperitoneal saline injections. Secondly, animals not injected with $\mathrm{ChB}$, but receiving intraperitoneal injections of either hypertonic saline or isotonic saline $90 \mathrm{~min}$ prior to the per- 
fusion fixation served as controls to the ChB-injected animals receiving intraperitoneal injections of both saline solutions.

Single antigen immunohistochemistry. Immunocytochemical visualication of $\mathrm{Cl} / \mathrm{B}$ or $c-f o s$ immunoreactivity (IR) was carried out on freefloating sections by a modified version of the avidin-biotin bridge method (Hsu et al., 1981). The sections were rinsed for $2 \times 10 \mathrm{~min}$ in KPBS (pH 7.4) to which $0.25 \%$ bovine serum albumin (BSA) and $0.1 \%$ Triton $\mathrm{X}-100$ (KPBS-BT) followed by a pretreatment in $1 \% \mathrm{H}_{2} \mathrm{O}_{2}$ in KPBS for $10 \mathrm{~min}$, and then incubated for $30 \mathrm{~min}$ in a $5 \%$ swine serum solution in KPBS containing $0.3 \%$ Triton X-100 and $1 \%$ BSA. The sections were then incubated for $24 \mathrm{hr}$ in either primary goat anti-ChB antiserum (List Biological Laboratories, CA), or in primary rabbit anti- $r$-fos antiserum raised against an $\mathrm{N}$-terminal sequence of rat $c$-fos (kindly provided by Drs. G. I. Evans and D. Hancock, London), at $4^{\circ} \mathrm{C}$ diluted 1:2000 (antiChB) or 1:4000 (anti-c-fos) in KPBS + 1\% BSA and 0.3\% Triton $\mathrm{X}-100$. After incubation in the primary antiserum the sections were washed in KPBS-BT for $3 \times 10 \mathrm{~min}$ followed by incubation for 60 $\mathrm{min}$ at room temperature in biotinylated donkey anti-goat $\operatorname{IgG}$ diluted 1:400 (Jackson Immunoresearch Lab., PA), or biotinylated swine antirabbit diluted 1:600 (DAKO, Glostrup, Denmark). The sections were then washed for $3 \times 10 \mathrm{~min}$ in KPBS-BT, and finally incubated for 60 min at room temperature in a streptavidin-biotinylated horseradish peroxidase complex (ABC) diluted 1:125 (DAKO). After washing in KPBS-BT for $10 \mathrm{~min}$, in KPBS alone for $10 \mathrm{~min}$ and $0.05 \mathrm{M}$ Tris/HCl buffer $(\mathrm{pH} \mathrm{7.6)} \mathrm{for} 10 \mathrm{~min}$, the sections were incubated for peroxidase activity in a solution of $0.025 \%$ diaminobenzidine $(\mathrm{DAB})$ in $0.05 \mathrm{M}$ Tris/ $\mathrm{HCl}$ buffer $(\mathrm{pH} 7.6)$ and $0.01 \% \mathrm{H}_{2} \mathrm{O}_{2}$ for $20 \mathrm{~min}$. The reaction was terminated by washing the sections in excessive amounts of water. Finally, the sections were mounted on gelatinized slides, dried and embedded in Depex. From each animal, a series of sections was quantified. Sections from comparable rostrocaudal levels were selected, and the distribution of $c$-fos-IR nuclei was drawn from a microscope equipped with a camera lucida device. Thus, the numbers of $c$-fos-IR nuclei within single sections rather than within the entire nucleus were compared between groups of differently treated animals. The specificity of the antiserum has been described in detail previously (Ebling et al., 1991). Control sections for single antigen immunohistochemistry were routinely processed by either omitting or replacing the primary antiserum with an equivalent concentration of either goat or rabbit preimmune serum. Using these procedures, all immunocytochemical staining was blocked.

Double antigen immunohistochemistry. Concomitant visualization of $c$-fos-IK and the retrogradely transported ChB-antigen was carried out by using a modified version of a dual-label immunocytochemical procedure (Hoffman et al., 1993) combining $\mathrm{NiSO}_{4}$ intensified DAB immunocytochemistry (c-fos) and conventional DAB-stained ChB immunocytochemistry. Alternatively, a combination of conventional DAB-stained $c$-fos immunocytochemistry and benzidine dihydrochloride (BDHC)-stained $\mathrm{ChB}$ immunocytochemistry was used (Mikkelsen et al., 1994).

In the first method, visualization of $c$-fos was carried out as described above, except for a concentration of 1:4000 of the primary antiserum was employed and the DAB-reaction product was blackened by reacting the sections in a solution of $(100 \mathrm{~mm} \mathrm{NiSO}, 125 \mathrm{~mm}$ Na acetate, 10 $\mathrm{mM}$ imidazole, $0.03 \% \mathrm{DAB}$, and $0.003 \% \mathrm{H}_{2} \mathrm{O}_{2}, \mathrm{pH} 6.5$ ). After visualization of $c$-fos-IR nuclei sections were washed thoroughly in KPBS (5 $\times 10 \mathrm{~min}$ ), and incubated overnight in primary goat anti-ChB (Vector, Burlingame, CA) diluted 1:2000 in KPBS containing 0.3\% Triton X-100 and $1 \%$ BSA. After incubation in the primary antiserum the sections were washed in KPBS-BT for $3 \times 10 \mathrm{~min}$ followed by incubation for $60 \mathrm{~min}$ at room temperature in biotinylated donkey anti-goat diluted 1:600 (Jackson Immunoresearch Lab). The sections were then washed for $3 \times 10 \mathrm{~min}$ in KPBS-BT, and finally incubated for $60 \mathrm{~min}$ at room temperature in $\mathrm{ABC}$ diluted 1:250 (Elite kit from Vector). After incubation in $A B C$, sections were reacted for peroxidase activity in a solution of $0.025 \%$ diaminobenzidine (DAB) in $0.05 \mathrm{M}$ Tris/ $\mathrm{HCl}$ buffer $\left(\mathrm{pH} \mathrm{7.6)}\right.$ and $0.01 \% \mathrm{H}_{2} \mathrm{O}_{2}$ for $20 \mathrm{~min}$, and the reaction was terminated by washing the sections in excessive amounts of distilled water. Finally, the sections were mounted on gelatinized slides, dried, and embedded in Depex.

In the second method, $c$-fos immunocytochemistry was carried out as described under single antigen detection whereas the $\mathrm{ChB}$ immunocytochemistry was carried out with a concentration of the primary antiserum of 1:4000. After incubation in the primary antiserum the sections were washed in KPBS-BT for $3 \times 10$ min followed by incubation for $60 \mathrm{~min}$ at room temperature in biotinylated donkey anti-goat diluted 1:600 (Jackson Immunoresearch Lab.). The sections were then washed for $3 \times 10 \mathrm{~min}$ in KPBS-BT, and finally incubated for $60 \mathrm{~min}$ at room temperature in $\mathrm{ABC}$ diluted 1:250 (Elitc kit from Vector). After incubation in ABC, sections were washed in KPBS for 10 min followed by washing for $3 \times 10 \mathrm{~min}$ in $1 \mathrm{M}$ acetate buffer $(\mathrm{pH} \mathrm{6.5)}$ ). The sections were then incubated in a solution of BDHC, which was prepared immediately before use. The BDHC solution was prepared by mixing equal amounts of the following solution $\mathrm{A}$ and $\mathrm{B}$ immediately prior to use. Solution (A) consisted of $90 \mathrm{ml}$ of distilled $\mathrm{H}_{2} \mathrm{O}$ at $50^{\circ} \mathrm{C}$ to which $10 \mathrm{mg}$ of $\mathrm{BDHC}$ was added and after vigorous stirring for $15 \mathrm{~min}$, the solution was filtered. Solution (B) consisted of $5 \mathrm{ml} 1 \mathrm{M}$ acetate buffer (pH 6.5) and $5 \mathrm{ml}$ distilled water to which $20 \mathrm{mg}$ of sodium nitroprusside was added. The reaction was started by adding $6 \mu \mathrm{l}$ of $\mathrm{H}_{2} \mathrm{O}_{2}(35 \%)$ to $100 \mathrm{ml}$ of BDHC solution. $\Lambda$ fter $20 \mathrm{~min}$ incubation at room temperature, the reaction was terminated by rinsing extensively in a postreaction solution consisting of $0.05 \mathrm{M}$ sodium acetate buffered saline (pH 6.5). Finally, the sections were rinsed twice in distilled $\mathrm{H}_{2} \mathrm{O}$ before being mounted out of this buffer onto glass slides coated with gelatin.

Cell counts of the proportion of retrogradely labeled neurons that also contained $c$-fos-IR nuclei were performed in animals were the $\mathrm{ChB}$ deposit had diffused throughout the entire central part of the PVN ie containing both the periventricular, the medial, and dorsal parvicellular subdivisions as well as the posterior magnocellular subdivision. However, cases in which the tracer deposit involved thalamic nuclei and the ventrally situated anterior hypothalamic are were discarded from further analysis. Cell counts of single one of six serial sections and corresponding plots of the distribution of labeled cells were obtained by using a Zeiss microscope fitled with a standard camera lucida. Rather than counting the entire number of labeled cells in the areas under investigation, representative and comparable sections from each of the cases were selected and the number of labeled cells were counted within the cytoarchitectonically defined confinements of the nuclear complexes, and the percentage of cells containing both antigens was calculated.

\section{Results}

Cholera toxin $B$ tracings. Injections of $\mathrm{ChB}$ were centered in the paraventricular nucleus (PVN), which was defined from cytoarchitectonic criteria and described with a nomenclature adopted from Swanson and Kuypers (1980). In most cases, the injection focus almost completely labeled the caudal part of the PVN and appeared to involve only the subparaventricular area and the most ventral portion of the thalamic nuclcus reuniens (Fig. 1).

Injections involving the dorsal part of the medial parvicellular subdivision and the posterior magnocellular division of the PVN contained highest numbers of $\mathrm{ChB}$ labeled neurons in the rostral periventricular specializations of the rostral part of the third ventricle, that is, the subfornical organ (SFO), the organum vasculosum of lamina terminalis (OVLT), and the median preoptic nucleus (MnPO) -all part of the cellular continuum called the anteroventral tip of third ventricle (Av3V). Retrogradely labeled perikarya with a similar morphology were distributed homogeneously throughout the various parts of the Av3V (Fig. 2).

In cases where the injection focus was centered in the medial parvicellular subdivision of the PVN, a substantial number of retrogradely labeled neurons was seen in the pontine parabrachial nucleus (PB) as well as in the region of catecholaminergic cells in the ventrolateral medulla (A1 and $\mathrm{C} 1$ ) and nucleus of the solitary tract (NTS).

The parabrachial nucleus (PB) of the rat consists of a medial subdivision lying ventromedially to the brachium conjunctivum, and a lateral subdivision lying dorsolaterally to the brachium conjunctivum (Fulwiler and Saper, 1984). From cytoarchitectonic criteria, it is possible to divide further the lateral subdivision into a dorsal, a central, a ventral, and an external lateral subdivision. Within the $\mathrm{PB}, \mathrm{ChB}$ labeled perikarya were preferentially confined to the central lateral and the dorsal lateral subnuclei 


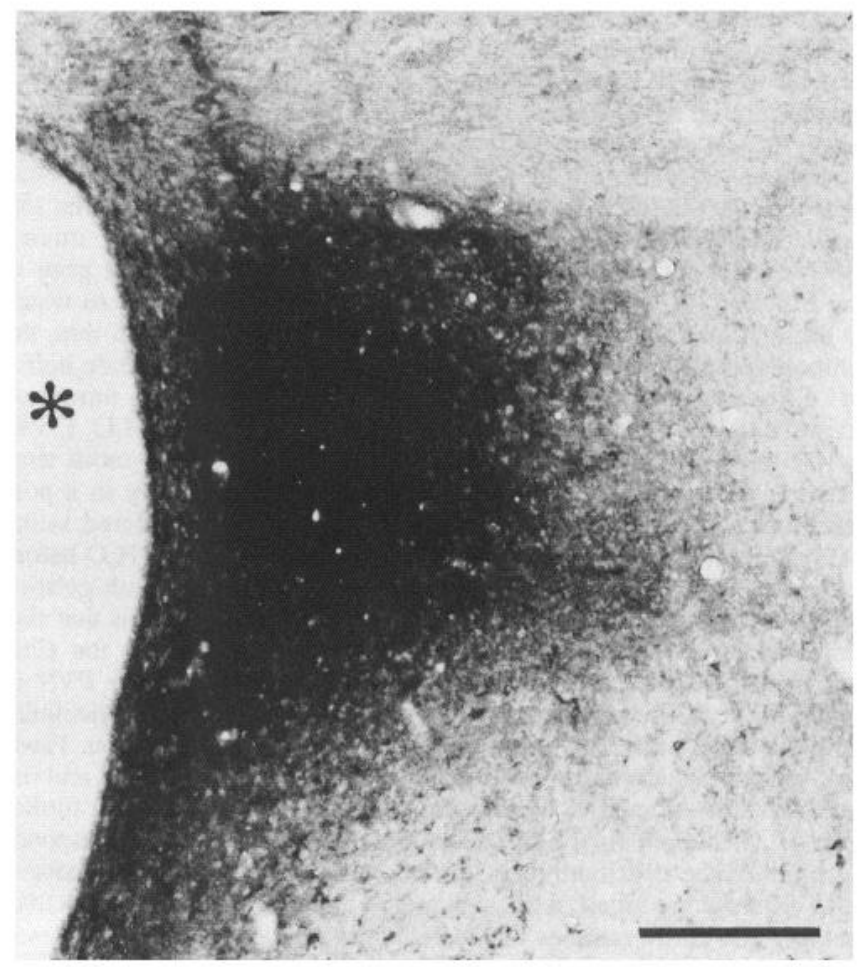

Figure 1. Low power photomicrograph showing the extent of a representative large injection of cholera toxin subunit $\mathrm{B}$ into the PVN as it appears after short survival time. Nonintensified DAB immunohistochemistry. Scale bar, $100 \mu \mathrm{m}$.

confirming that neurons of these areas are the major constituents of a projection from the PB to the PVN (Fig. 3).

Within the caudal medulla oblongata, retrogradely labeled cells in the ventrolateral medulla were present throughout the rostrocaudal extent of the catecholaminergic A1/C1 area, which are positioned at the dorsolateral pole of the lateral reticular nucleus. The labeled cells of the A1/C1 area appeared as group of identical perikarya clustered within a network of intertwining dendritic processes (Fig. 4). A few scattered retrogradely labeled perikarya were observed in the part of the medullary reticular formation lying interspersed between the A1 and A2. The nucleus of the solitary tract (NTS) embrace a variety of neurons which can be further characterized from their cytoarchitecture, neurochemistry and connectivity (Kalia and Fuxe, 1985; Kalia et al., 1985a,b). Retrogradely labeled neurons were restricted to the caudal areas of the NTS largely corresponding to the catecholaminergic A2 area containing the bulk of noradrenergic perikarya within the NTS (Fig. $4 B$ ). Within this part of the NTS which preferentially lies caudal to the obex, retrogradely labeled perikarya were mostly observed in caudal part of the medial subdivision, while occasional labeled perikarya were seen in the adjacent nucleus commissuralis (Fig. 4C). Retrogradely labeled neurons were neither observed within the dorsal motor nucleus of the vagus nerve nor in the area postrema.

$\mathrm{C}$-fos immunocytochemistry. The distribution of $c$-fos-immunoreactive ( $c$-fos-IR) nuclei in areas of the forebrain and selected brainstem nuclei of nonhandled animals was evaluated and served as a reference throughout of the study. To evaluate whether the mere presence of the $\mathrm{ChB}$ tracer influenced the expression of $c$-fos in the brain, a series of sections from animals iontophoretically injected with $\mathrm{ChB} 1$ week prior to fixation but otherwise nonmanipulated was investigated for $c$-fos-IR. The number of $c$-fos-IR nuclei in certain areas of interest was quantified, and differences between ChB injected animals and in noninjected animals were not observed. Although not all areas expressing $c$-fos-IR nuclei were subjected to a quantitative analysis, did the intracerebral presence of the $\mathrm{ChB}$ tracer not appear to influence the pattern of basal $c$-fos-IR expression. In addition, the presence of intracerebral $\mathrm{ChB}$ tracer was without influence upon the number of $c$-fos-IR nuclei expressed in response to intraperitoneal injections of either isotonic or hypertonic saline (Table 1). Thus, the presence of $\mathrm{ChB}$ did not facilitate the effect of hypertonic "stress" upon the expression of $c$-fos-IR and in the following paragraphs, animals with intracerebral $\mathrm{ChB}$ tracer are considered to respond normally to the challenge of an intraperitoneal hypertonic saline and no special reference is made to absence or presence of the tracer.

In nonhandled animals, scattered labeling of $c$-fos-IR nuclei was observed throughout the cerebral cortex, the paraventricular and other midline thalamic nuclei, and the septohippocampal complex. Very sparse labeling was observed within the hypothalamic paraventricular (PVN) and supraoptic (SON) nuclei. Caudal to this hypothalamic level, sparse labeling of the ventromedial, dorsomedial, and arcuate nuclei was observed. In nonhandled animals, hardly no $c$-fos-IR nuclei were observed within the SFO, the MnPO, and the OVLT (Table 1). Another circumventricular organ - the area postrema-was also devoid of $c$-fosIR nuclei in nonhandled animals. The pontine parabrachial nucleus was completely devoid of $c$-fos-IR nuclei in ChB-injected non-handled animals. Within the brainstem, a few c-fos-IR nuclei were observed in those areas containing ascending catecholaminergic neurons, that is, the NTS and the ventrolateral medulla. In nonhandled animals, $c$-fos-IR nuclei were practically absent in these catecholaminergic brainstem regions (Table 1).

The number of $c$-fos-IR nuclei induced by intraperitoneal injection of hypertonic saline was fairly constant in individual areas, confirming the reproducibility of the "stress" paradigm, and significantly induced expression of $c$-fos-IR was seen in the SFO, the OVLT, the MnPO, and the AP. Within the hypothalamus, all areas containing magnocellular hypothalamo-neurohypophysial neurons including the SON and the nucleus circularis displayed a very pronounced expression of $c$-fos-IR nuclei. In contrast, intraperitoneal injections of isotonic saline did not induce $c$-fos expression in circumventricular organs and hypothalamic magnocellular areas. Within the SFO, $c$-fos-IR nuclei were heterogeneously distributed with a clear preponderance in the periphery of the organ, leaving the central core sparsely populated with $c$-fos-IR nuclei (Fig. 6). Further rostrally in the Av3V, a high number of $c$-fos-IR nuclei was seen in the OVLT an the $\mathrm{MnPO}$ of animals given intraperitoneal hypertonic saline (Fig. $7 A, B)$, while animals given intraperitoneal isotonic saline did not express $c$-fos-IR nuclei in these areas (Fig. $7 C$ ). However, in the quantitative validation of $c$-fos-IR nuclei no attempts were done to delineate further these structures, and the figures given in Table 1 are average estimates from the entire area. Intraperitoneal injection of hypertonic saline also significantly induced the expression of $c$-fos-IR nuclei in a number of the brainstem nuclei: the PB, the NTS and within the A1 and C1 regions of the ventrolateral medulla oblongata (Table 1).

Intraperitoneal administration of hypertonic saline induced a significant expression of $c$-fos-IR nuclei in the PB, while intraperitoneal injections of isotonic saline had no effect upon $c$-fosIR expression in the PB (Fig. 7). The $c$-fos-IR nuclei induced 

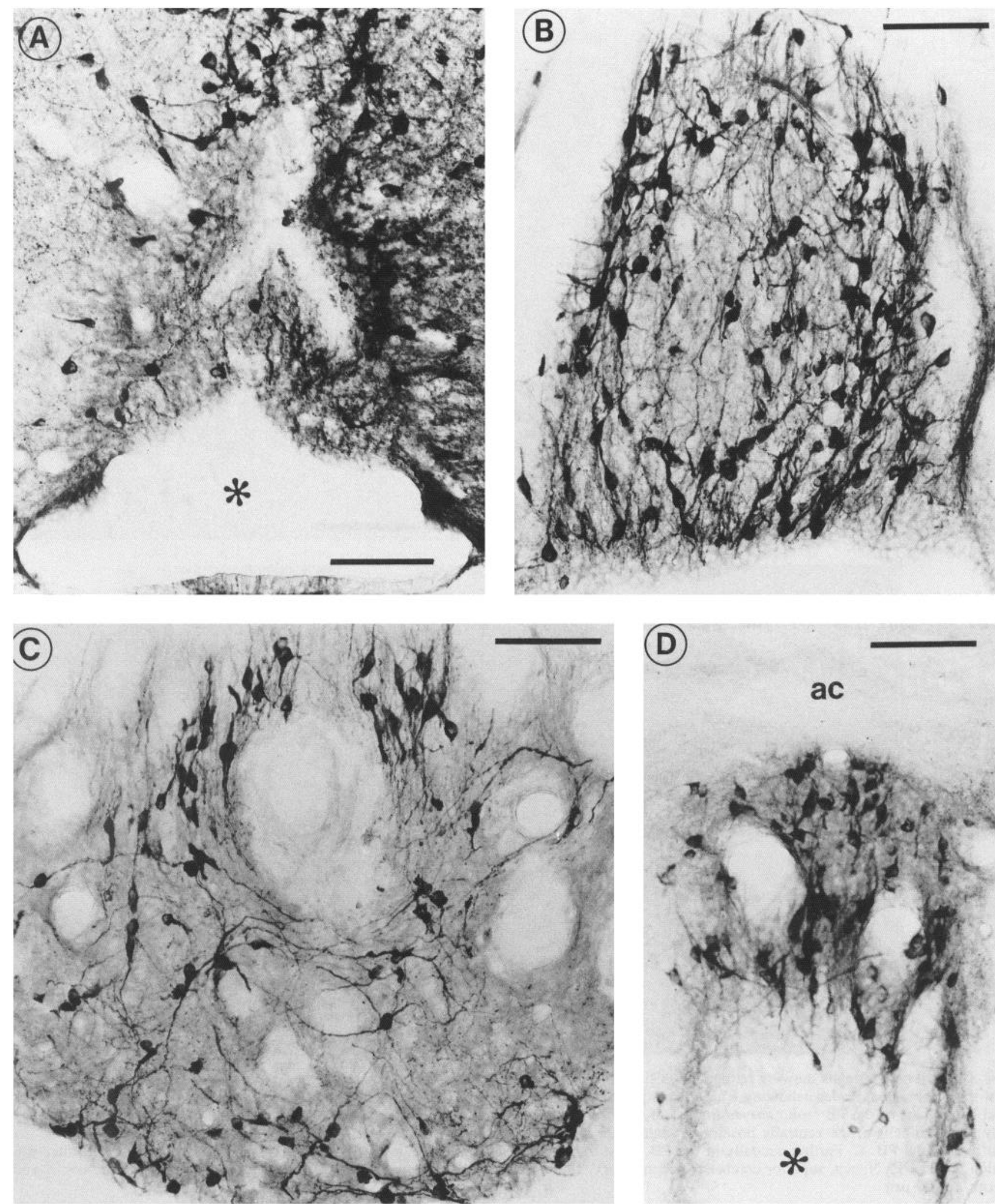

Figure 2. Photomicrographs showing retrogradely ChB-labeled perikarya in the circumventricular organs of the anteroventral tip of the third ventricle. Numerous ChB-labeled perikarya are observed in the OVLT and adjacent areas $(A)$. Within the most rostral part of the SFO, a dense cluster of retrogradely labeled perikarya possessing extensive dendritic arborizations is seen $(B)$. Further caudal in the SFO fewer retrogradely labeled perikarya are seen $(C)$. Within the median preoptic nucleus retrogradely labeled cells are distributed homogeneously throughout the nucleus (D). Nonintensified DAB immunohistochemistry. Scale bars, $100 \mu \mathrm{m}$. 

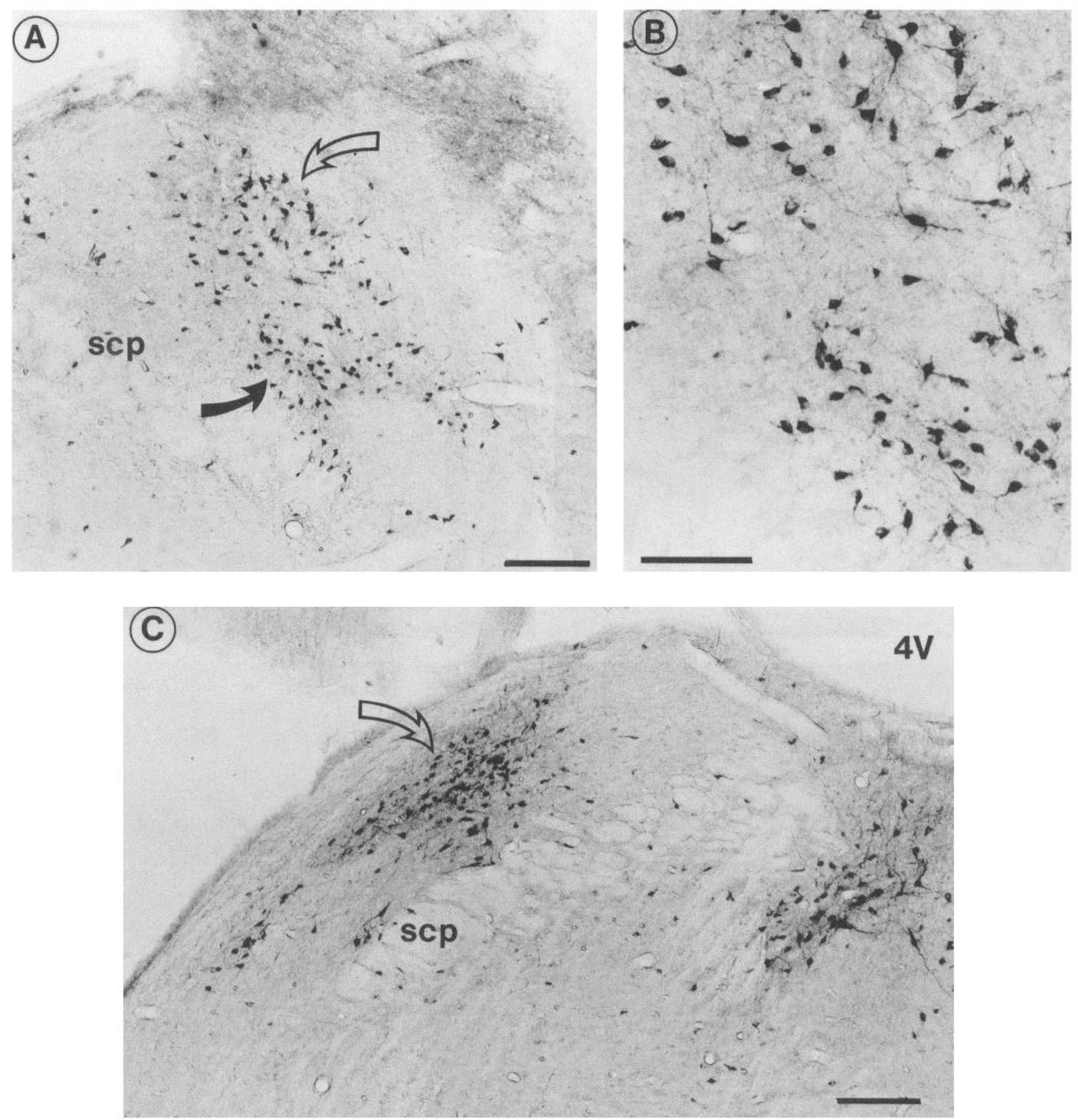

Figure 3. Photomicrographs showing retrogradely ChB-labeled perikarya in the parabrachial nucleus. A, Low power photomicrograph of the rostral part of the parabrachial nucleus showing a high density of retrogradely labeled cells in the dorsal lateral part (open curved arrow) as well as in the central lateral part of the PB (solid curved arrow). B, A medium power photomicrograph of the lateral part of the PB is shown in $A$ where it is clearly seen that cells of the ventrally positioned central lateral part of the PB have less extensive dendritic arborizations than those of the dorsal lateral part of the PB. $C$, Further caudally in the PB, most retrogradely labeled cells are found in the dorsal lateral part of the PB after a ChB injection into the PVN; $s c p$, superior cerebellar peduncle; $4 \mathrm{~V}$, fourth ventricle. Nonintensified DAB immunohistochemistry. Scale bars: $A$ and $C$, $250 \mu \mathrm{m} ; B, 100 \mu \mathrm{m}$.

by the "stress" of intraperitoneal hypertonic saline preferentially emerged in the external lateral and the dorsal lateral subdivisions of the PB, whereas a moderate expression $c$-fos-IR was seen in the central lateral subdivision of the PB. In contrast, the medial and ventral lateral subdivisions were completely devoid of $c$-fosIR nuclei. Also the Kölliker-Fuse nucleus, which is a collection of large triangular perikarya lying ventrally to the external lateral division of the $\mathrm{PB}$, was completely devoid of $c$-fos-IR elements.

Using the obex as a point of separation, the noradrenergic A2 part of the dorsally situated NTS was arbitrarily divided into a rostral and a caudal region. Further rostrally, the NTS was regarded as the adrenergic $\mathrm{C} 2$ area. Similarly, the ventrolateral 

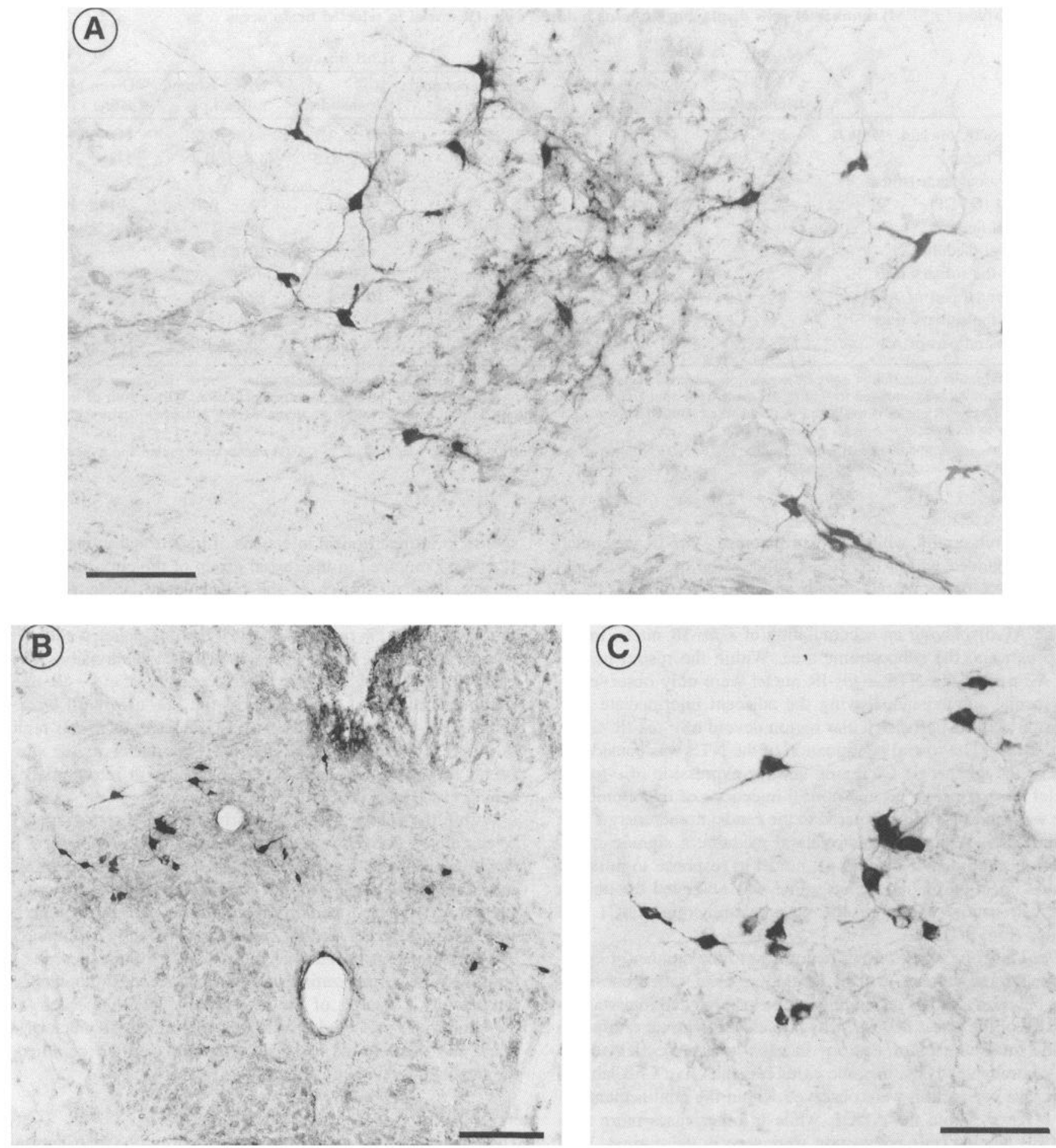

Figure 4. Photomicrographs showing retrogradely labeled perikarya in the catecholaminergic cell groups of the caudal brainstem after a ChB injection into the PVN. Within the ventrolateral medulla (A1 group) retrogradely labeled cells are scattered throughout the area (A), while retrogradely labeled cells in the nucleus of the solitary tract (A2 group) are concentrated within the medial subnucleus of the NTS $(B)$. A higher magnification of the retrogradely labeled cells showed in $B$ is shown in $(C)$. Nonintensified DAB immunohistochemistry. Scale bars: $A$ and $C$, $100 \mu$ m; $B$, $250 \mu \mathrm{m}$.

medulla was divided into a caudal region corresponding to the noradrenergic Al area and a rostral region corresponding to the adrenergic $\mathrm{C} 1$ area. Intraperitoneal injections of isotonic induced a slight but significantly higher expression of $c$-fos-IR nuclei in the A2 than observed in nonhandled animals. However, the number of $c$-fos-IR nuclei in the A2 of animals given intraperitoneal hypertonic saline far exceeded that observed in animals subjected to injections of isotonic saline (Table 1). Intraperitoneal injections of isotonic saline had no effect upon the number of $c$-fos-IR nuclei in the $\mathrm{A} 1 / \mathrm{C} 1$ region and the rostrally situated $\mathrm{C} 2$ part of the NTS. The expression of $c$-fos-IR nuclei emerged preferentially in the medial subdivision of the NTS and the nu- 
Table 1. Mean ( \pm SEM) number of cells displaying sitmulus induced $c$-fos-IR nuclei in selected brain areas

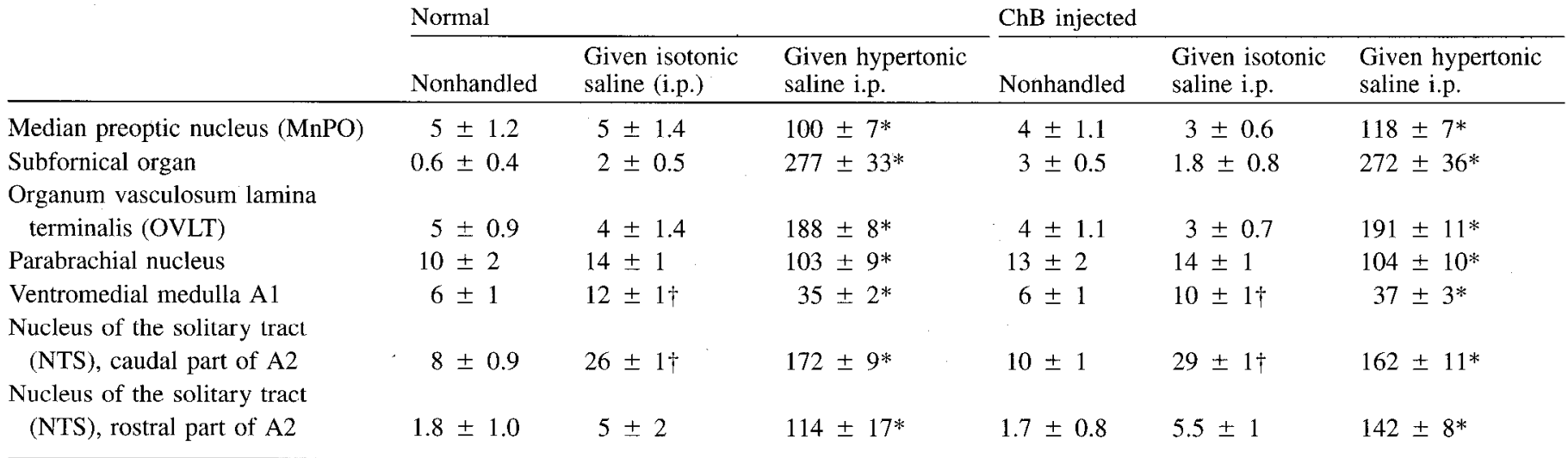

Data are quantilative validation of $c$-fos-IR expression induced in selected brain nuclei by the intraperitoneal hypertonic saline "stress" paradigm. Figures obtained from naive animals are compared to figures obtained from animals intracerebrally injected with ChB $7 \mathrm{~d}$ prior to experimentation. Within both of these groups, expression of $c$-fos-IR nuclei is evaluated in nonhandled animals, animals given intraperitoneal isotonic saline, or animals given intraperitoneal hypertonic saline 90 min prior to fixation. $n=6$ in all groups.

$*, p<0.05$ versus nonhandled and isotonic saline i.p. (ANOVA followed by Scheffe's post hoc analysis). $\dagger, p<0.05$ versus nonhandled and hypertonic saline i.p. (ANOVA).

cleus commissuralis, while the expression of $c$-fos-IR was much less pronounced within the dorsal subdivision of the NTS and the adjacent parasolitarius region and dorsal strip (Fig. 8). A heterogeneous distribution of $c$-fos-IR nuclei was also observed in the AP displaying an accumulation of $c$-fos-IR nuclei in the deep part and the subpostreme area. Within the rostral part of the A2 part of the NTS, $c$-fos-IR nuclei were only observed in the medial subdivision, leaving the adjacent intermediate subdivision and the periventricular region devoid of $c$-fos-IR nuclei (Fig. 9A,B). The rostral continuation of the NTS was considered part of the adrenergic $\mathrm{C} 2$ region and the expression of $c$-fos-IR nuclei in response to intraperitoneal injections of hypertonic saline was modest when compared to the caudal noradrenergic part of the NTS. Within the ventrolateral medulla, a significant increase in the number of $c$-fos-IR nuclei in response to intraperitoneal injection of hypertonic saline was observed throughout the rostrocaudal extent of the catecholaminergic $\mathrm{A} 1 / \mathrm{Cl}$ cell groups (Fig. 9C).

Dual labeling experiments. In contrast to the number of $c$-fosIR nuclei, the number of $\mathrm{ChB}$ labeled neurons varied considerably between animals depending on the location and in particular the size of the tracer deposit, which made an accurate estimation of the total number of neurons in each area projecting to the PVN unreliable. Thus, in some cases less than five $\mathrm{ChB}$ labeled perikarya per section were observed within the confinements of the NTS or within the $\mathrm{A} 1 / \mathrm{C} 1$, while in other cases more than $40 \mathrm{ChB}$ labeled cells per section were seen in these areas. Well aware of the fact that the dual labeling experiments preferentially are qualitative, the percentage of the perikarya containing both the $\mathrm{ChB}$ and the $c$-fos antigens was, however, calculated and it was observed that the extent of PVN projecting $c$-fos-IR perikarya varied considerably (Table 2 ). Within the subdivisions of the Av3V, the percentage of colocalization was $48 \pm 4 \%$ ( $n$ $=11)$ in the SFO, $56 \pm 3 \%(n=7)$ in the MnPO, and $34 \pm$ $5 \%(n=5)$ in the OVLT. Examples of dual labeled neurons in the Av3V containing both the retrogradely transported $\mathrm{ChB}$ tracer and $c$-fos-IR nuclei are presented in Figure 10.

The parabrachial nucleus was found both to contain retrogradely labeled perikarya and to express $c$-fos-IR nuclei in re- sponse to intraperitoneal injections of hypertonic saline (see Fig. $12 A-C)$. Compared to the rostral group of the circumventricular organs, however, fewer of the retrogradely labcled pcrikarya were concomitantly $c$-fos-IR, giving a percentage of colocalization of $19 \pm 2 \%(n=8)$. Most of the dual labeled cells were seen in the central lateral and dorsal lateral subdivisions of the PB (Fig. 11). Despite of the relative paucity of $c$-fos-IR nuclei in the central lateral subdivision of the PB, nearly all $c$-fos-IR nuclei were observed in retrogradely labeled cells in this region. In contrast, the majority of the c-fos-IR nuclei in the dorsal lateral division of the $\mathrm{PB}$ were not present in retrogradely labeled cells (Fig. 11).

Within the caudal medulla, nearly all of the retrogradely labeled cells in the ventrolateral medulla (VLM) A1/C1 were immunoreactive to both antigens, reflected by a percentage of colocalization of $89 \pm 6 \%(n=5)$ (Fig. $12 D)$. Also the majority of retrogradely labeled perikarya lying scattered throughout the area between the A1 and A2 were concomitantly immunoreactive for $c$-fos, but because of the paucity of these neurons the proportion of colocalization was not calculated. In contrast, approximately a quarter of the retrogradely labeled perikarya of the caudal A2 part of the NTS contained $c$-fos-IR nuclei (Fig. $12 E$ ), and those found to be dual labeled were all confined to the medial subdivision of the NTS (Fig. 13).

\section{Discussion}

The present study gives a detailed account on the distribution of $r$-fos-IR expression in neurons responding to the stimulus of an intraperitoneal injection of hypertonic saline in combination with a description of the connectivity to the hypothalamic PVN. The applied stimulus has previously been shown to induce a secretory response of vasopressin from magnocellular vasopressinergic neurons of the hypothalamo-neurohypophysial system as well as hypophysiotrophic corticotrophin-releasing factor (CRF) containing neurons of the PVN (Dunn et al., 1973; Irvine et al., 1989; Dohanics et al., 1991). The secretory response from magnocellular neurons is completely blunted in hyponatremic animals indicating that the sensitivity of magnocellular hypothalamo-neurohypophysial neurons is critically dependent on the 

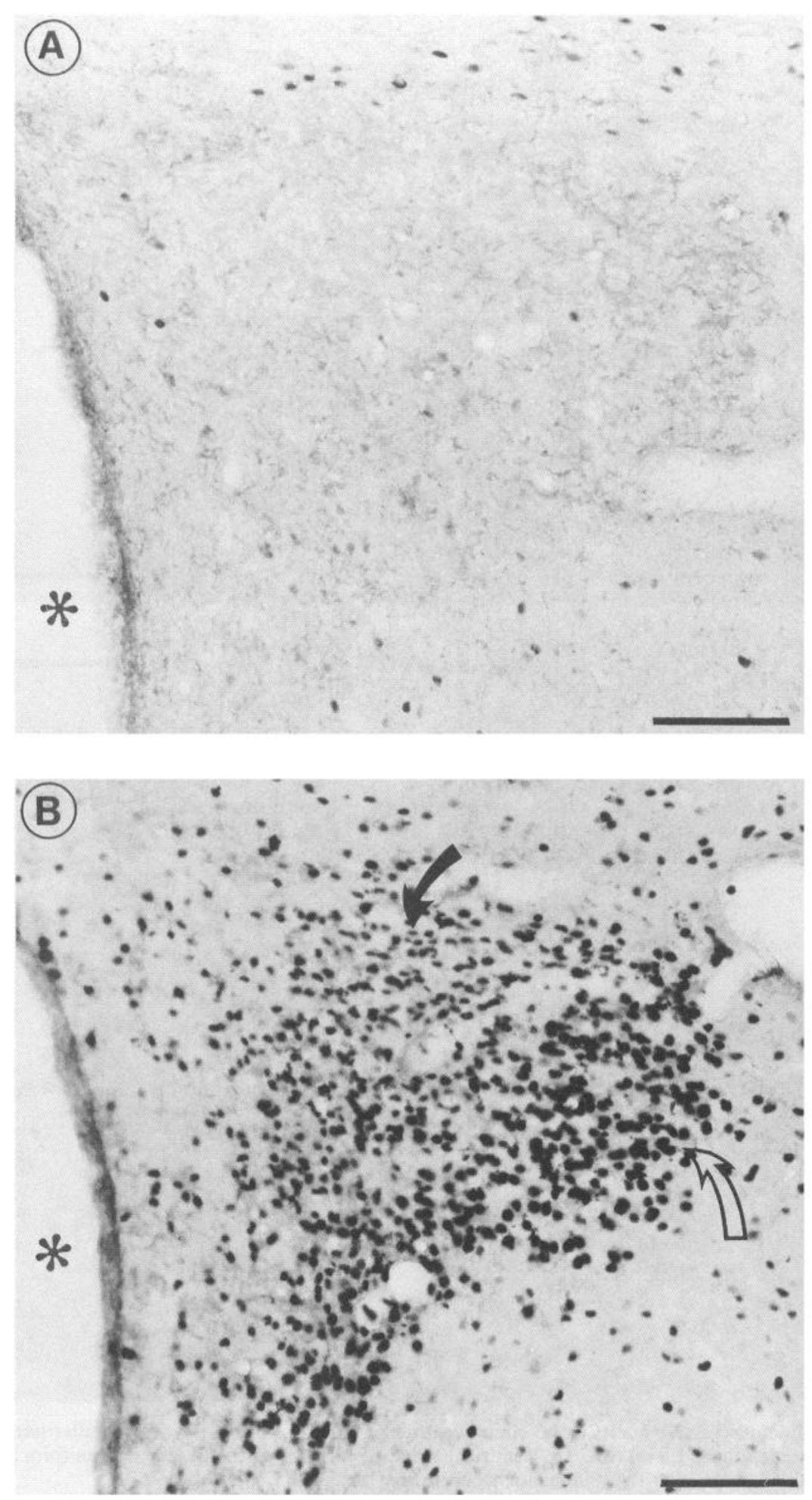

Figure 5. Medium power photomicrograph of frontal sections through the PVN, 90 min after intraperitoneal administration of either isotonic saline $(A)$ or hypertonic saline $(1.5 \mathrm{M})(B)$. The application of the "stress" paradigm induced $c$-fos-IR expression in both the posterior magnocellular subdivision (open curved arrow) and the dorsal part of the medial parvicellular subdivision where the hypophysiotrophic cells projecting to the external zone of the median eminence are massed (solid curved arrow). Nonintensified DAB immunohistochemistry. Scale bars, $100 \mu \mathrm{m}$.

plasma osmolality "set-point" present at the time of stimulation. In contrast, hyponatremia does not fully inhibit the ACTH response to a hypertonic challenge indicating that a stressor not related to an osmotic mechanism mediates the activation of hypophysiotrophic CRF/AVP neurons in the medial parvicellular part of the PVN (Dohanics et al., 1991). Hence, the presently used acute osmotic challenge should be regarded as a combination of a "stress-full" and an osmotic stimulation, of which the "stressor"-branch is likely to consists of both the pain associated with peritoneal irritation and arterial hypotension due to the loss of plasma water which ultimately lead to a stimulation of parvicellular CRF/AVP neurons.

With the advent of immunocytochemical detection of $c$-fos or other immediate early genes as a tool for labeling of recent activation of individual neurons, it has been possible to gain further information about the neuronal circuitry that participates in 

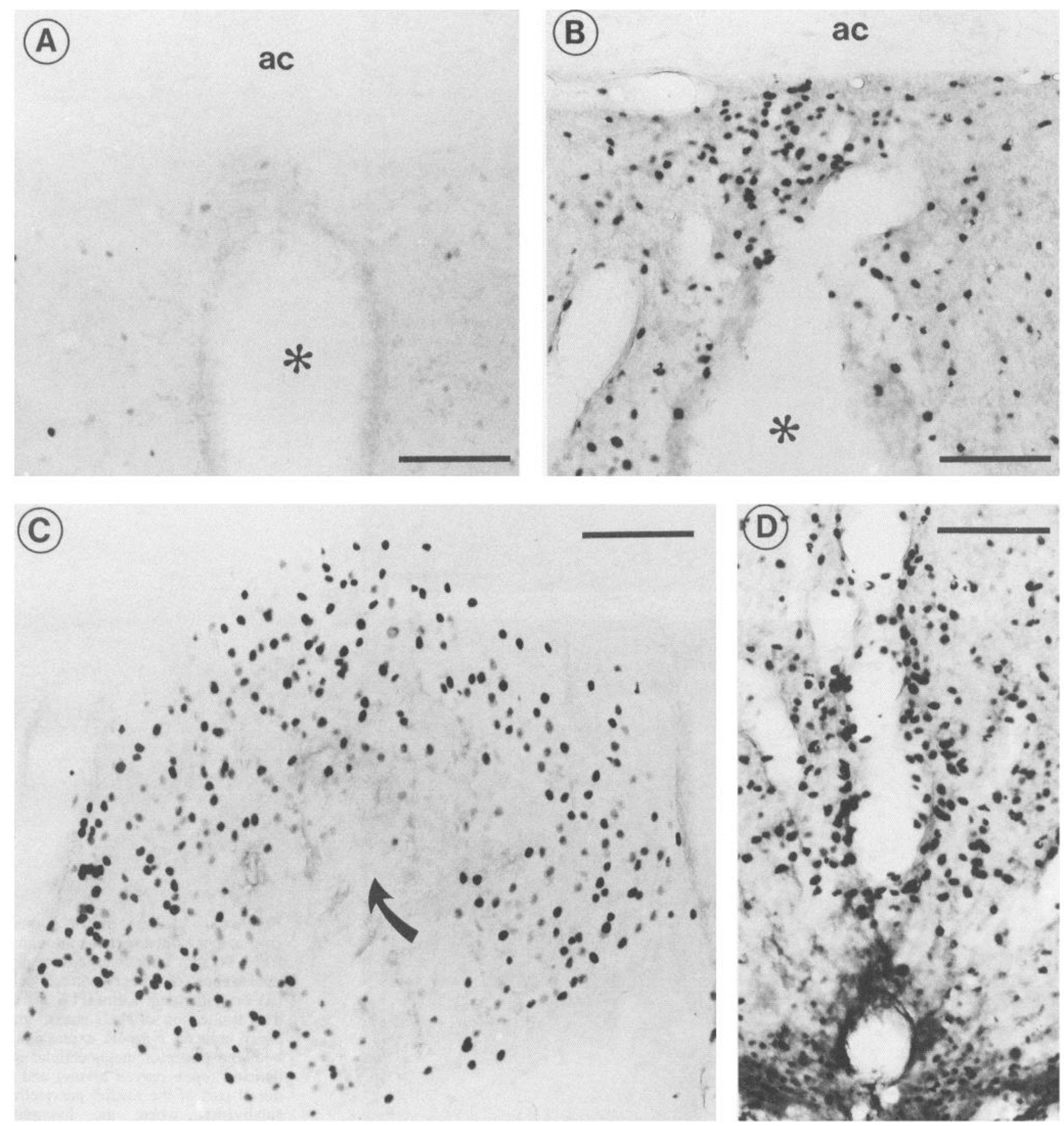

Figure 6. Photomicrographs demonstrating $c$-fos-immunoreactive nuclei in the circumventricular organs of the Av3V, 90 min after intraperitoneal administration of either isotonic saline $(A)$ or hypertonic saline $(1.5 \mathrm{M})(B, C, D)$. Within the median preoptic nucleus $(A$ and $B)$ a uniform distribution of $c$-fos-IR nuclei was seen throughout the nucleus. Nonintensified DAB immunohistochemistry. Scale bars, $100 \mu \mathrm{m}$.

the activation of specific neuronal system (Sagar et al., 1988; Sheng and Greenberg, 1990; Morgan and Curran, 1991). A number of experiments have described the pattern of $c$-fos-IR expression in the SON and the PVN as well as the rostral circumventricular organs after application of the presently employed "stress" paradigm (Sagar et al., 1988; Carter and Murphy, 1990; Sharp et al., 1991; Giovanelli and Bloom, 1992; Leng et al., 1992). After application of the "stress" paradigm $c$-fos-IR nuclei was observed both within the medial parvicellular part of the PVN as well as in the magnocellular parts of PVN confirming the mixed nature of the stimulus. A multitude of various "stress" models induces c-fos expression in the hypophysiotrophic neurons of the medial parvicellular part of the PVN suggesting that stimulation of the CRF containing neurons of the HA-axis is in many cases accompanied by a transient transcription of the $c$-fos gene (Ceccatelli et al., 1989; Imaki et al., 1992).

The combination of $c$-fos detection and $\mathrm{ChB}$ could potentially be jeopardized by unwanted side effects induced by the tracer 

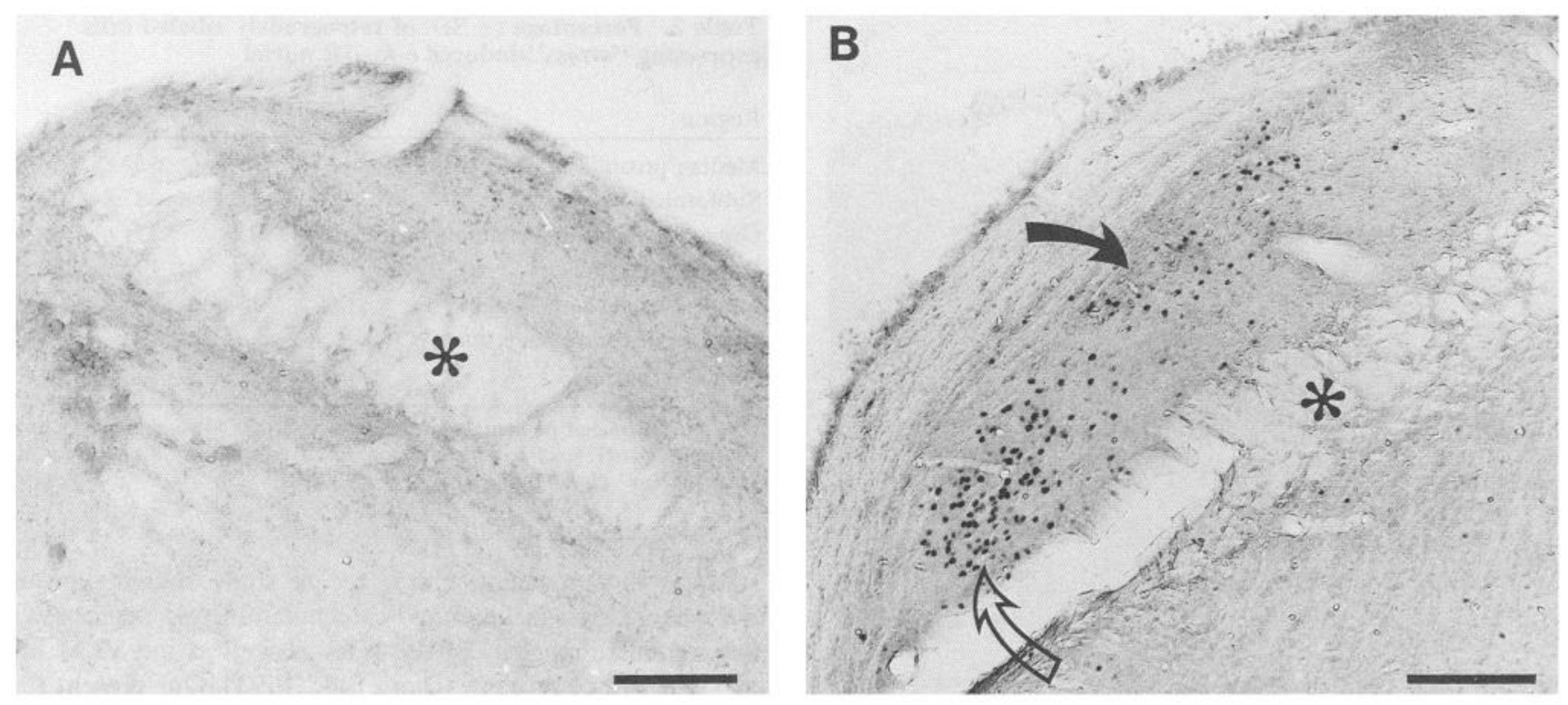

Figure 7. Low power photomicrograph of frontal sections demonstrating $c$-fos-immunoreactive nuclei within the parabrachial nucleus 90 min after application of either intraperitoneal isotonic saline $(A)$ the hypertonic saline "stress" paradigm $(B)$. Intraperitoneal injection of isotonic saline had no effect upon the expression of $c$-fos-IR nuclei in the PB, whereas hypertonic saline markedly induced the expression of $c$-fos-IR. The largest number of nuclei expressing $c$-fos-IR is seen in the external lateral part (open curved arrow), whereas considerable fewer $c$-fos-IR nuclei are seen in the dorsal lateral part of the PB (solid curved arrow). scp, Superior cerebellar peduncle. Nonintensified DAB immunohistochemistry. Scale bars, $250 \mu \mathrm{m}$.

upon immediate early gene expression in neurons. However, the mere presence of the $\mathrm{ChB}$ tracer had no influence upon the expression of $c$-fos in areas under investigation, confirming that this tracer can be used reliably in combination with $c$-fos studies of neuronal activation. In contrast, the intraperitoneal injection procedure induced a slight but significant increase in the expression of $c$-fos-IR in neurons of the A2 catecholaminergic brainstem area. This induction was, however, moderate compared to the robust induction of $c$-fos expression observed after application of the hyperosmotic "stress" paradigm in the same area, suggesting that the discomfort related to the needle penetrating the skin constitutes a minor "stress" inducing a slight activation of $c$-fos expression in the $\mathrm{A} 2$ brainstem area.

\section{Topography of neurons activated by intraperitoneal hypertonic saline}

Little is known about the pattern of intraperitoneal hypertonic saline induced $c$-fos expression in areas known to project to the PVN, but the extensive stimulation of $c$-fos-IR expression within the brainstem catecholaminergic areas observed in the present
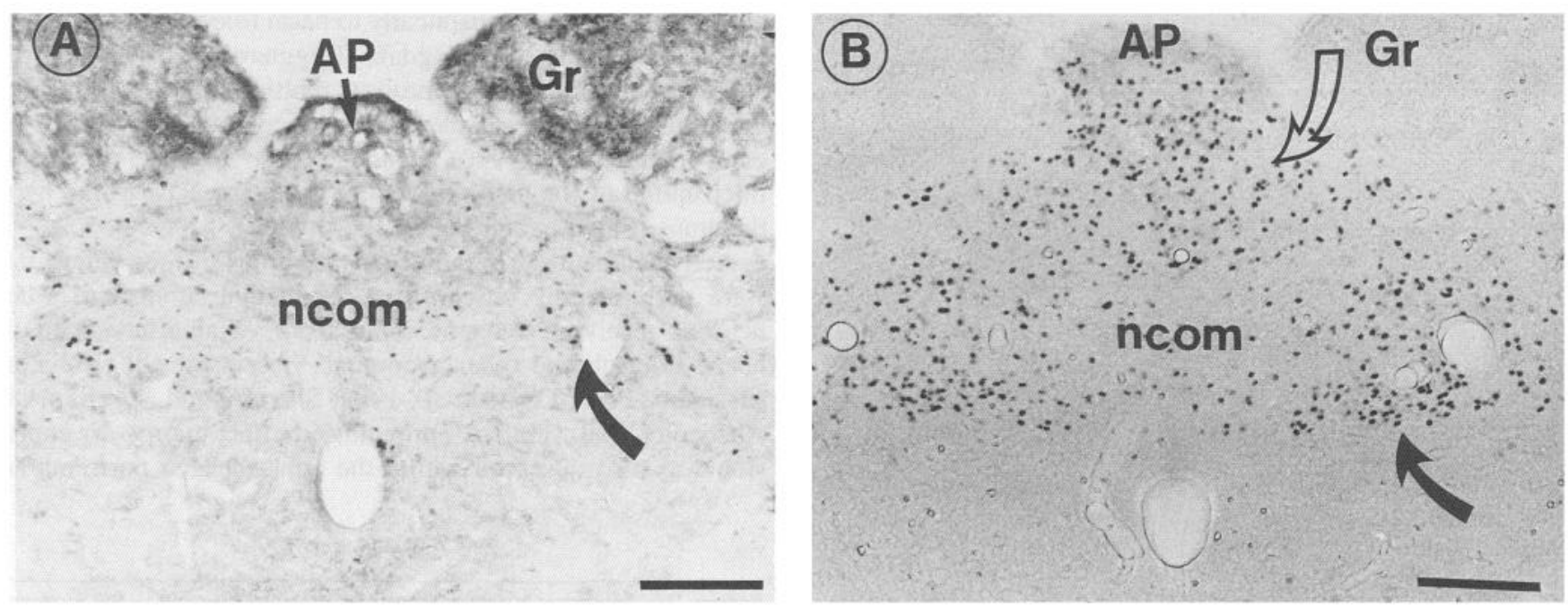

Figure 8. Low power photomicrograph of frontal sections demonstrating $c$-fos-immunoreactive nuclei within the caudal part of the nucleus of the solitary tract (NTS) 90 min after application of either intraperitoneal isotonic saline $(A)$ the hypertonic saline "stress" paradigm $(B)$. Intraperitoneal injection of isotonic saline induced expression of a low number of $c$-fos-IR nuclei in the medial subdivision of the NTS (solid curved arrows), while the hypertonic saline "stress" paradigm markedly induced the expression of $c$-fos-IR in the NTS and the adjacent subcommissural nucleus (open curved arrow) and the area postrema (asterisk). Nonintensified DAB immunohistochemistry. Scale bars, $250 \mu \mathrm{m}$. 

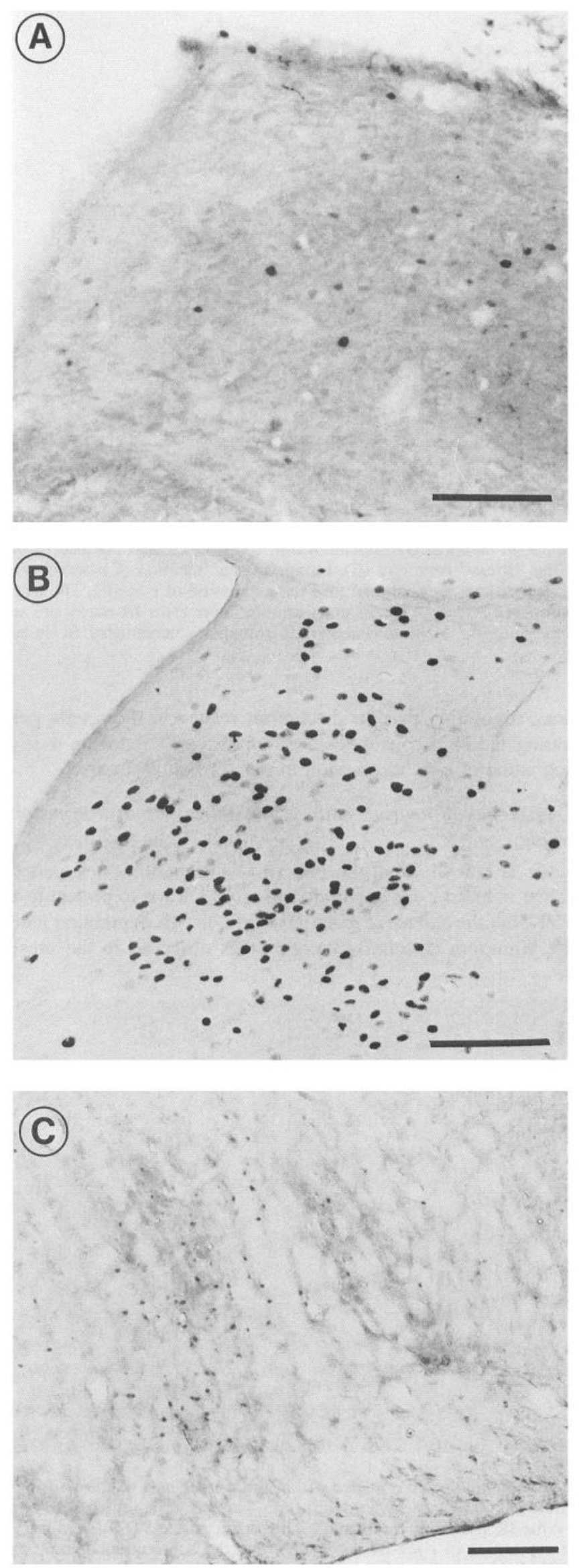

Table 2. Percentage $( \pm$ SD) of retrogradely labeled cells expressing "stress"-induced $c$-fos-IR nuclei

\begin{tabular}{ll} 
Region & $\%$ \\
\hline Median preoptic nucleus (MnPO) & $56 \pm 3(n=7)$ \\
Subfornical organ & $48 \pm 3(n=11)$ \\
Organum vasculosum lamina terminalis (OVLT) & $35 \pm 5(n=5)$ \\
Parabrachial nucleus & $19 \pm 2(n=8)$ \\
$\quad$ Ventromedial medulla A1 & $89 \pm 6(n=5)$ \\
$\quad$ Nucleus of the solitary tract (NTS), & \\
$\quad$ caudal part of A2 & $24 \pm 3(n=5)$
\end{tabular}

Data are estimated percentages (mean $\pm \mathrm{SD}$ ) of ChB-labeled cells also expressing $c$-fos-IR nuclei in various regions after application of the i.p. hypertonic "stress" paradigm.

study is in agreement with a recent study showing profound $c$-fos expression in identified catecholaminergic neurons within the medial subnucleus of the NTS as well as the VLM in rats exposed to hemorrhage (Dun et al., 1993). Our present results are, however, contrasted by an earlier report specifically stating that intraperitoneal injections of hypertonic saline neither induce $c$-fos-IR expression within the A1 area nor in the A2 area (Giovanelli and Bloom, 1992). The reason for this discrepancy is unknown, but may partly be explained by variable stimulus strength or by the shorter postinjection survival time $(30 \mathrm{~min})$ chosen in that study. In a series of preliminary experiments, however, we have observed $c$-fos-IR expression in both the A1 and $\mathrm{A} 2$ after intraperitoneal injections of hypertonic saline at postinjection survival times of both 30 or $60 \mathrm{~min}$. The present study reveal further the functional topography of neurons in the NTS activated by intraperitoneal hypertonic saline injections. In the rat, the nucleus of the solitary tract receives input from the gustatory and the general visceral cranial nerves as well as from the trigeminal nerve, and the major outflows from this complex are to medullary neurons involved in cardiovascular and oromotor responses or to higher centers engaged with perception (Norgren, 1985; Ruggiero et al., 1994). The pathways from the NTS to higher centers are organized in two distinct routes one of which projects monosynaptically to basal forebrain areas like the hypothalamus and the amygdala (Ruggiero et al., 1994; Swanson, 1987), while the other projects multisynaptically to the thalamocortical system via the ipsilateral pontine parabrachial nucleus (Whitehead, 1990), which is also a site for synaptic interruption of the pathway leading from the NTS to the hypothalamus (Fulwiler and Saper, 1984).

Activated neurons in the nuclear complex of the solitary tract were preferentially observed in the medial subnucleus where neurons receiving synaptic input from vagal afferents of the heart, stomach and other abdominal viscera prevail (Kalia and Mesulam, 1980; Leslie et al., 1982; Sharpiro and Miselis, 1985; Altschuler et al., 1989). A pronounced effect upon $c$-fos expression was also observed within the adjacent area postrema and

$\leftarrow$

Figure 9. Medium power photomicrographs showing c-fos-immunoreactive nuclei in the rostral part of the $\mathrm{A} 2$ after application of either intraperitoneal isotonic saline $(A)$ the hypertonic saline "stress" paradigm $(B)$. Scale bars, $100 \mu \mathrm{m}$. $C$ demonstrates the "stress" induced expression of $c$-fos-IR nuclei in the A1 catecholaminergic cell group of the ventrolateral medulla. Nonintensified DAB immunohistochemistry. Scale bar, $250 \mu \mathrm{m}$. 

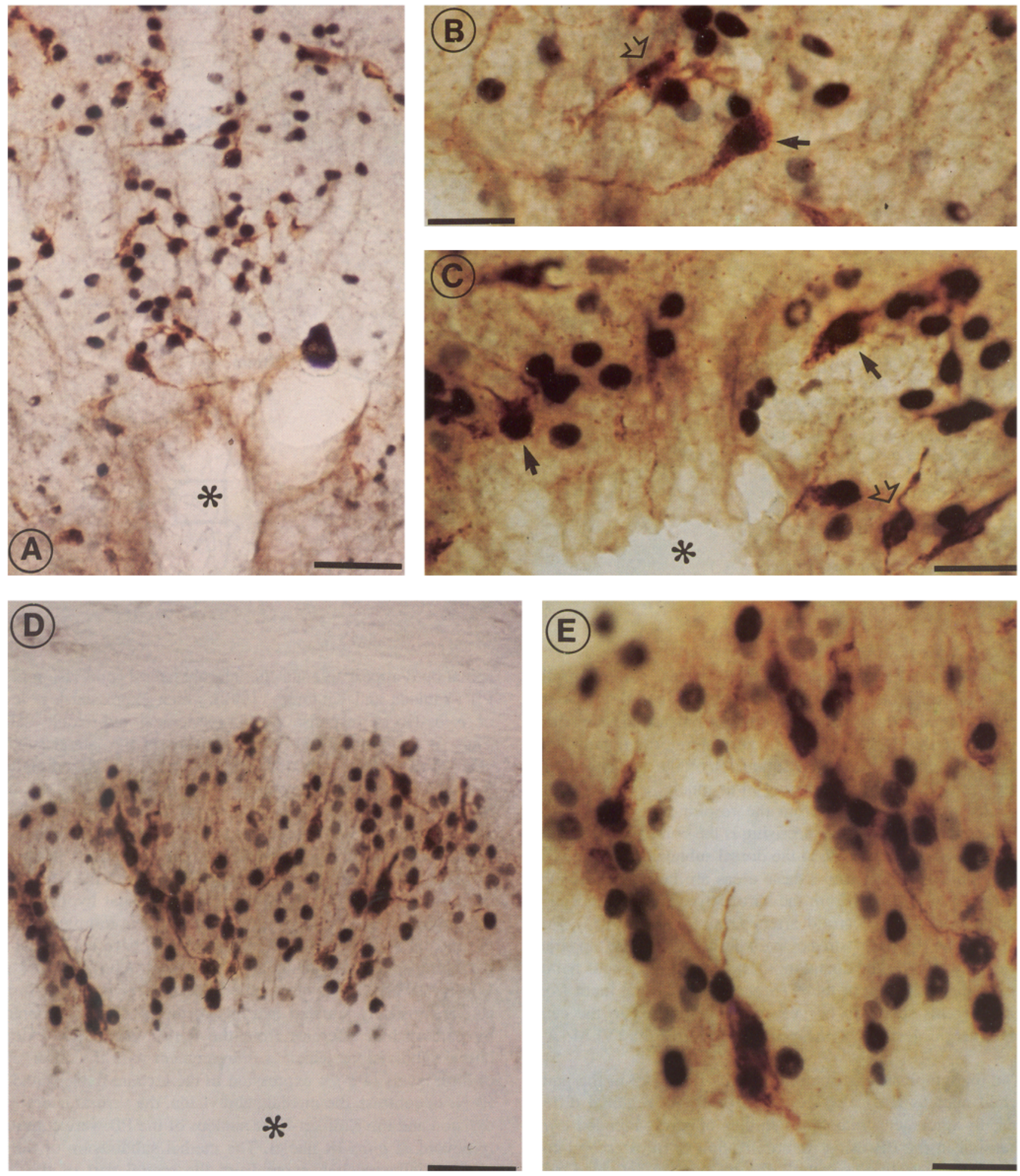

Figure 10. Series of Ni-DAB/DAB dual-labeling immunocytochemical stainings showing retrogradely ChB-labeled cells (DAB) in rostral circumventricular organs after $\mathrm{ChB}$ injections into the PVN and $c$-fos-IR (Ni-DAB) expression in response to intraperitoneal hypertonic saline. $A$ and $B$ are low and high power photomicrographs, respectively, of the OVLT, $C$ is a photomicrograph of the MnPO, while $D$ and $E$ are low and high power photomicrographs, respectively, of the SFO. In all panels, open arrows point to retrogradely labeled cells not containing $c$-fos-IR nuclei, while solid arrows point to retrogradely labeled cells with $c$-fos-IR nuclei. Asterisks indicate the third ventricle. Scale bars: $A$ and $D, 50 \mu$ m; $B$, $C$, and $E, 25 \mu \mathrm{m}$ 
Figure 11. Line drawing of the parabrachial nucleus demonstrating location of $\mathrm{ChB}$ labeled and $c$-fos-IR cells. Framed area on the drawing of the lower right corner depicts the localization of the area where cells containing immunoreactivities for either $\mathrm{ChB}(\times)$, $c$-fos $(\mathrm{O})$, or both $(\mathrm{)})$ were found. The majority of dual-labeled cells is seen in the central lateral and dorsal lateral subdivisions of the PB. $K F$, KölikerFuse nucleus; $s c p$, superior cerebellar peduncle; $s c t v$, ventral spinocerebellar tract; $P C G$, pontine central gray; $L D T$, laterodorsal tegmental nucleus; $P B m m$, medial part of the parabrachial nucleus; $4 \mathrm{~V}$, fourth ventricle.

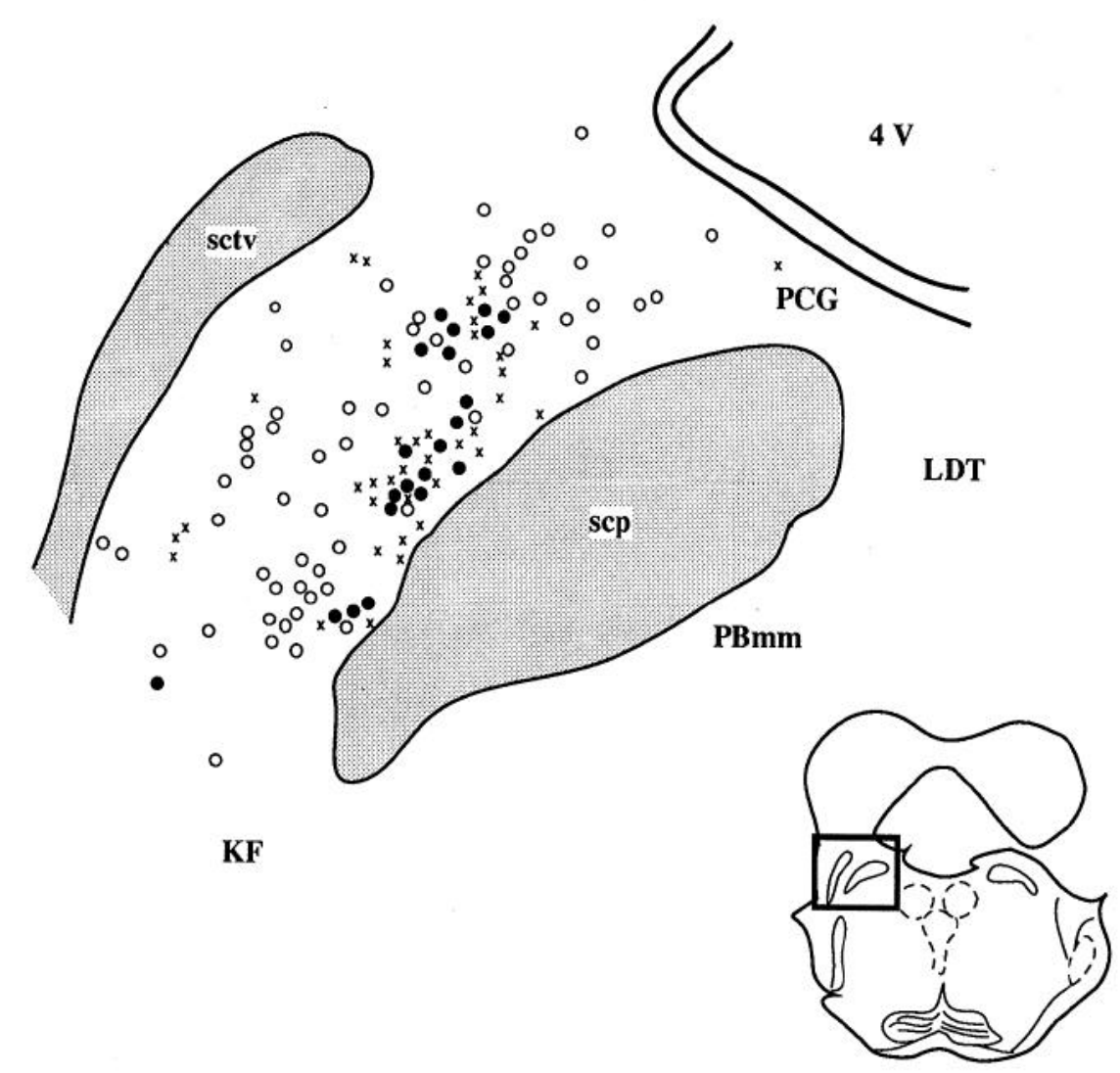

the subpostreme area bordering the nucleus commissuralis, which is in agreement with earlier studies suggesting that the AP plays some role in water and sodium balance. The obvious absence of $c$-fos-IR nuclei in the ventrolateral, the dorsolateral, the ventral and the interstitial subnuclei of the nucleus of the solitary tract is far from surprising in as much these areas preferentially receive afferents from the respiratory system (Kalia and Mesulam, 1980). More surprising is the comparatively moderate expression of $c$-fos-IR in the dorsal subnucleus of the NTS and the dorsal strip, because these areas are target sites for the termination of afferents from the baroceptive and chemoceptive specializations of the carotid artery (Kalia et al., 1985a). Furthermore, the applied "stress" paradigm conveys no apparent stimulatory input to the dorsal motor nucleus of the vagus nerve, whereas the activation of the NTS neurons receiving input from vagal afferents seems to be very potently relayed to the catecholaminergic neurons of the ventrolateral medulla (VLM, A1/ C1).

The topographical distribution of $c$-fos-IR nuclei in the parabrachial nucleus (PB) also displayed profound regional differences. In agreement with other studies of stress-induced $c$-fos expression in the PB using immobilization or intracerebral colchicine administration as stimuli, the majority of activated cells are seen in the external lateral and dorsal lateral subdivisions (Kainu et al., 1993) with a lesser degree of activation in the central lateral subdivision. These areas of the $\mathrm{PB}$ receive afferent inputs from the medial subnucleus of the caudal part of the NTS (predominantly viscerosensory) as well as from pars caudalis of the spinal trigeminal nucleus (Herbert et al., 1990; Whitehead, 1990) suggesting that general somatosensory stimuli (pain) converge with interoceptive inputs in the lateral PB. However, the bulk of sensory inputs from layer I of the dorsal horn of the spinal cord appear to enter the internal lateral subdivision of the PB (Yamada and Kitamura, 1992) which expressed low levels of $c$-fos-IR in response to intraperitoneal hypertonic saline. Thus, it seems most likely that neurons in the lateral subdivisions of the PB are activated to express $c$-fos via ascending input from the viscerosensory neurons of the NTS, although a careful study over the graded time course of $c$-fos expression in response to the applied stimulus is needed to further enlighten this matter. The organization of the efferent projections of the PB displays distinct topographical organization with the lateral subdivisions preferentially projecting to the medial hypothalamus, the amygdala and the bed nucleus of the stria terminalis, while the medial subdivision preferentially projects to the lateral hypothalamus, the amygdala and cortical structures (Saper and Loewy, 1980). Thus, the applied stimulus is likely to further activate rostrally situated neurons in the medial hypothalamus by parabrachial efferents from the dorsal lateral and external lateral subdivisions which is in agreement with the observation of high levels of $c$-fos expression in the arcuate nucleus and the PVN. In contrast, the medial subdivision, the ventral lateral subdivision and the Kölliker-Fuse nucleus of the PB were completely devoid of $c$-fos-IR nuclei. The medial subdivision of the PB preferentially receives input from the rostral part of the NTS (predominantly gustatory), the rostral part of the spinal trigeminal nucleus and the parvicellular reticular formation of the caudal medulla (Herbert et al., 1990; Whitehead, 1990), all areas that in terms of $c$-fos expression were unaffected by the applied stimulus.

The majority of the neurons within the circumventricular organs of the anteroventral tip of the third ventricle (Av3V) were activated by the applied "stress" paradigm. The neural projection connecting the SFO/MnPO to the magnocellular hypothal- 
amo-neurohypophysial neurons of the SON and PVN either directly or via synaptic interruption in the medial preoptic area is postulated to participate in the secretory response of the neurohypophysis to an osmotic challenge (Bisset and Chowdrey, 1988; Leng et al., 1988, 1989; Hatton, 1990). The neurons situated within the Av3V may respond directly to perturbations of plasma osmolality or they may be activated by a polysynaptic circuit linking the viscerosensory neurons of the medial subdivision of the NTS with the SFO (Ruggiero et al., 1994).

\section{Distribution of neurons potentially mediating neuroendocrine responses of $P V N$ neurons to intraperitoneal hypertonic saline}

The present retrograde in vivo tracing experiments as well as other studies have shown that the PVN receives direct projections from the NTS, the VLM, the PB as well as the circumventricular organs bordering the rostral tip of the third ventricle (Swanson, 1987). These afferent projections terminate in topographically distinct regions in such a way that inputs to the magnocellular vasopressinergic neurons appear to arise primarily from the catecholaminergic $\mathrm{A} 1 / \mathrm{C} 1$, the $\mathrm{SFO}$ and the $\mathrm{Av} 3 \mathrm{~V}$, whereas the region where parvicellular CRF containing neurons prevail also receive inputs from the NTS, the PB (Miselis, 1981; Sawchenko and Swanson, 1982a; Fulwiler and Saper, 1984; Sawchenko et al., 1985; Cunningham and Sawchenko, 1988; Cunningham et al., 1990).

Systemic administration of angiotensin II increases plasma concentrations of vasopressin and oxytocin and increases blood pressure via actions in the CNS (Johnson and Gross, 1993), and lesions of the SFO or its ventral efferent projections abolishes these responses (Mangiapane and Simpson, 1980; Lind et al., 1983) suggesting that circulating angiotensin II exert this effect through SFO efferents projecting to the hypothalamo-neurohypophysial neurons of the PVN and SON. However, angiotensin II is also present within the central neurons conveying information from the SFO to the PVN. Thus, dual-labeling experiments and electrophysiological experiments have clearly demonstrated the presence of a excitatory angiotensin II containing pathway activated by osmotic stimuli originating from the SFO to the vasopressinergic neurons of the PVN (Jhamandas et al., 1989; $\mathrm{Li}$ and Ferguson, 1993). In this context, it seems likely that part of the SFO neurons presently demonstrated to project to the PVN are angiotensinergic neurons activated by the osmotic perturbation of intraperitoneal hypertonic saline. Recently, it has been demonstrated that lesions of the ventral lamina terminalis completely blocks osmotically induced alterations of CRF mRNA expression in both magno- and parvicellular neurons of the PVN suggesting that information about plasma osmolality is conveyed to these neuroendocrine neurons via the OVLT (Kovács and Sawchenko, 1993). Within the SFO and the Av3V, the number of $c$-fos-IR nuclei far exceeded that of retrogradely labeled cells probably reflecting that the contralateral PVN as well as the SON also receive afferent input from the $\mathrm{SFO} / \mathrm{Av} 3 \mathrm{~V}$. It was more surprising that only about $50 \%$ of the retrogradely labeled cells were activated by the osmotic stimulus. However, it may be that the SFO should be considered a functional heterogeneous structure with some of its neurons having a higher activation threshold for Fos-expression than provided by the currently employed osmotic stimulus. The heterogeneity of SFO neurons projecting to the PVN has recently been confirmed by a electrophysiological experiment demonstrating that SFO neurons innervate both magnocellular neuroendocrine neurons as well as other neurons, some of which are actually inhibited by the SFO (Li and Ferguson, 1993).

Although some controversies exists, it is generally believed that CRF secretion from the parvicellular PVN and median eminence and of ACTH from the adenohypophysis is facilitated by noradrenergic and adrenergic inputs from the locus coeruleus and the caudal brainstem (Plotsky et al., 1989). Stimulation of the ventral noradrenergic bundle increases the release of CRF into the portal circulation (Plotsky, 1987), and catecholamine depleting neurotoxic lesions of this bundle greatly reduces the CRF release (Eckland et al., 1988). Although our present data do not phenotypically characterize the neurons projecting to the PVN, most of the neurons in the caudal VLM are noradrenergic (A1) while neurons in the rostral part of the VLM are adrenergic, and dual-labeling experiments combining retrograde tracing with immunocytochemistry for catecholamine synthesizing enzymes have confirmed that the majority of neurons projecting from the A1 to the PVN is also noradrenergic while the majority of $\mathrm{C} 1$ neurons projecting to the PVN is adrenergic (Sawchenko and Swanson, 1982b; Sawchenko et al., 1985). The high degree of $c$-fos-IR expression in retrogradely labeled neurons in the caudal VLM suggests that most of the ascending noradrenergic neurons of the Al are activated by the applied "stress" paradigm.

In contrast to the VLM, the immunohistochemical pattern of catecholamine synthesizing enzymes is far more complex in the NTS, but coexistence of $c$-fos-IR nuclei and the retrograde tracer was predominantly seen in the medial nucleus of the NTS where noradrenergic neurons prevail (Kalia et al., 1985a), suggesting that the PVN projecting neurons activated by the applied "stress" are noradrenergic. Only about a quarter of the retrogradcly labcled cells in the NTS were activated by the "stress" paradigm suggesting that not all neurons in this area respond to intraperitoneal hypertonic saline. Other transmitters such as neuropeptide $\mathrm{Y}$, neurotensin, somatostatin, ChAT (cholinergic), and substance P (Sawchenko et al., 1985; Riche et al., 1990; Zardetto-Smith and Gray, 1990; Bittencourt et al., 1991) have been identified in neurons of the NTS projecting to the PVN, and it is likely that a number of the retrogradely labeled cells represents such neurons. However, further studies are needed to clarify whether these neurons actually respond with $c$-fos expression to the currently applied stimulus-if not they are likely candidates to the nonresponding PVN projecting cells presently observed. The presence of large number of $c$-fos-IR nuclei in the regions of the NTS where retrogradely labeled neurons were sparse indicate that local interneurons and neurons projecting to other distant areas different from the PVN are also activated by the "stress" paradigm.

In a series of experiments combining electrophysiological recordings and anterograde neuronal tract tracing it has been demonstrated that the projections from the PB to the PVN arise chiefly from the dorsal lateral, the central lateral, and the external lateral subdivisions (Jhamandas et al., 1992) corresponding exactly to the areas expressing $c$-fos in response to intraperitoneal hypertonic saline. Furthermore, the projection from the PB to the PVN preferentially terminates in the medial parvicellular part of the PVN and activates nonmagnocellular neurons of the medial parvicellular part of the PVN. Rather few of the neurons projecting from the parabrachial nucleus to the PVN were concomitantly labeled for $c$-fos-IR suggesting that they were activated to a lesser extent than those of other areas projecting to the PVN eg the SFO and A1/C1. However, most of the retrogradely labeled neurons in the central lateral subdivision also 

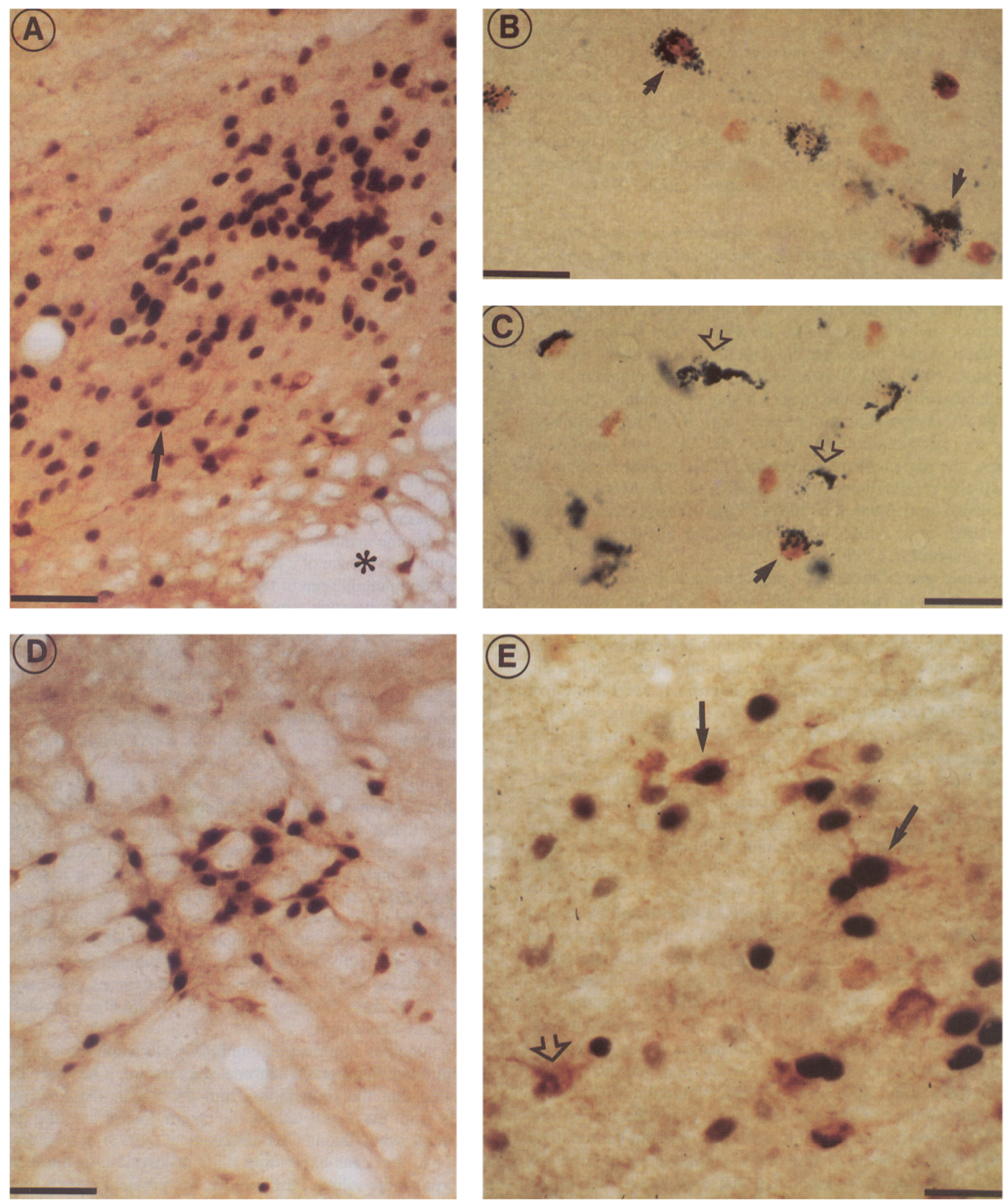

Figure 12. Series of dual-labeling immunocytochemistry showing retrogradely ChB-labeled cells in various brainstem areas after ChB injections into the PVN and $c$-fos-IR expression in response to intraperitoneal hypertonic saline. Numerous Ni-DAB labeled $c$-fos-IR nuclei are seen in the lateral parabrachial nucleus among which few ChB-labeled cells (nonintensified DAB) are scattered $(A)$. A dual-labeled cell is seen just lateral to the superior cerebellar peduncle (asterisk). The distribution of dual labeled cells in the external lateral $(B)$ and dorsal lateral $(C)$ subdivisions of the parabrachial nucleus was investigated further with a dual-labeling technique combining ChB-staining with BDHC as a chromogen and $c$-fosIR-staining with DAB as a chromogen. Dual-labeled cells are found in both subdivisions (solid arrows), while a few retrogradely labeled cells without $c$-fos-IR expression is seen in the dorsal lateral subdivision (open arrows). Further caudal in the ventrolateral medulla (A1) most retrogradely labeled cells (nonintensified DAB) also contain Ni-DAB labeled $c$-fos-IR nuclei $(D)$. Both dual-labeled cells (solid arrows, nonintensified DAB 

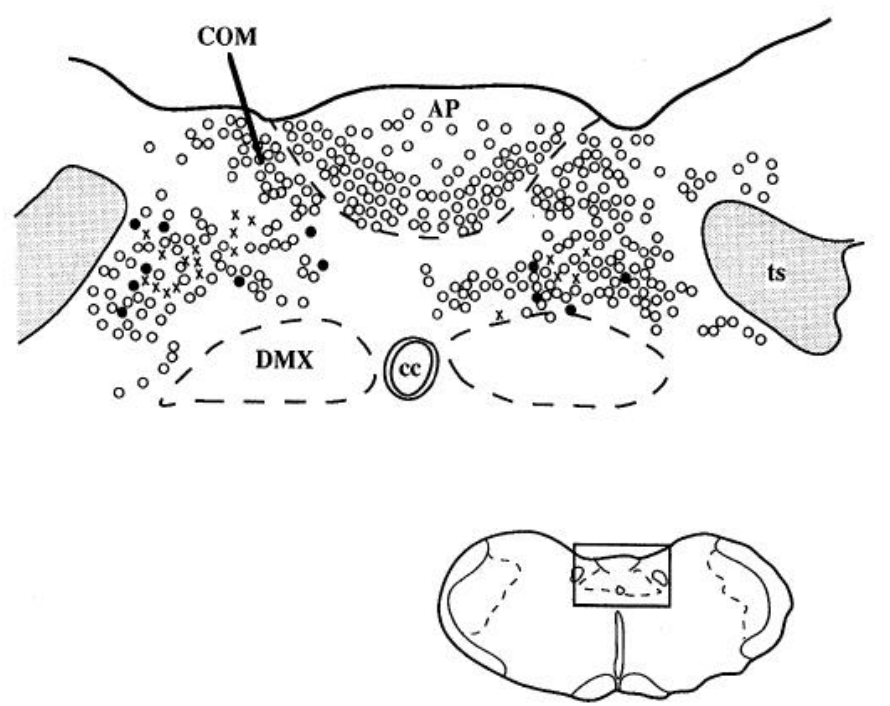

Figure 13. Line drawing of the nucleus of the solitary tract at a level just caudal to the calamus scriptorius. Framed area on the drawing of the lower right corner depicts the localization of the area where cells containing immunoreactivities for either $\mathrm{ChB}(\times), c$-fos $(\mathrm{O})$, or both (O) were found. Note that most dual-labeled cells are found in the medial subnucleus of the NTS. $A P$, area postrema; $c c$, canalis centralis; $C O M$, nucleus commissuralis; $D M X$, dorsal vagal motor nucleus; $t$, tractus solitarius.

expressed a $c$-fos-IR nucleus whereas fewer of the retrogradely labeled cells in the dorsal lateral subdivision expressed $c$-fos-IR, suggesting that a functional differentiation of the PB efferents to the PVN may exists. Although the stimulatory input to the nonmagnocellular PVN from the lateral PB predominates, an inhibitory input to these cells has also been demonstrated (Jhamandas et al., 1992) and it may be that the dorsal lateral subdivision preferentially inhibits neurons of the PVN while those of the central lateral subdivision are predominantly stimulatory to neurons of the PVN.

Considering the large number of retrogradely labeled neurons in the PB, very few of these retrogradely labeled neurons were activated by intraperitoneal hypcrtonic saline suggesting the currently studied "stress" response of neuroendocrine CRF neurons in the PVN is not under a predominant direct influence of the PB. Rather, it seems as if the majority of activated PB neurons project to other regions of the central nervous system such as the amygdala and other hypothalamic nuclei (Saper and Loewy, 1980; Fulwiler and Saper, 1984). Several transmitter candidates - mainly neuropeptides-have been identified within neurons of the PB. Thus, calcitonin gene-related peptide (CGRP), substance $\mathrm{P}$ and neurotensin are colocalized in neurons projecting to the central amygdala and CRF/leu-enkephalin containing neurons of the dorsal lateral PB project to the medial preoptic area (Lind and Swanson, 1984; Shimada et al., 1985; Block and Hoffman, 1987; Shinohara et al., 1988). A number of studies suggests that the functional implication of such a CGRP/neurotensin pathway is to convey visceroceptive information from the cardiovascular system via the PB to the central amygdaloid nucleus (Darlington and Ward, 1985; Nguyen et al., 1986;
Brown and Gray, 1988). Also, various types of "stress" induce Fos-expression in CGRP/neurotensin immunoreactive cells of the lateral PB and CGRP/neurotensin containing nerve terminals have been shown to innervate cells exhibiting Fos immunoreactivity after "stress" in the central amygdala (Honkaniemi, 1993; Kainu et al., 1993), supporting the view that the PB relay "stress" related information to limbic areas. It may, however, be that other types of "stressors" may activate $c$-fos-IR expression in PB neurons projecting to the PVN, and future studies await to clarify the functional role of the PB efferents to the PVN.

In conclusion, our study demonstrates that $c$-fos-IR expression induced by intraperitoneal hypertonic saline is localized within neurons projecting to neuroendocrine neurons of the PVN, and hence the present data contribute to elucidate neuronal circuits mediating physiological and neuroendocrine effects of a combined osmotic and hemodynamic "stress." In some areas, nearly all of the neurons projecting to the PVN were activated, whereas in other areas c-fos-IR expression prevailed in neurons not projecting directly to the PVN, indicating that the applied "stress" paradigm appears to differentially activate neurons connected to the PVN. Ongoing work will help to elucidate whether other types of "stress" activates yet other neuronal projections to the final common effector of the "stress" responsive HA-axis.

\section{References}

Altschuler SM, Bao X, Bieger D, Hopkins DA, Miselis RR (1989) Viscerotropic representation of the upper alimentary tract in the rat: sensory ganglia and nuclei of the solitary and spinal trigeminal tracts. J Comp Neurol 283:248-268.

Bisset GW, Chowdrey HS (1988) Control of release of vasopressin by neuroendocrine reflexes. Q J Exp Physiol 73:811-872.

Bittencourt JC, Benoit R, Sawchenko PE (1991) Distribution and origins of substance P-immunoreactive projections to the paraventricular and supraoptic nuclei: partial overlap with ascending catecholaminergic projections. J Chem Neuroanat 4:63-78.

Block CH, Hoffman GE (1987) Neuropeptide and monoamine components of the parabrachial pontine complex. Peptides 8:267-283.

Brown MR, Gray TS (1988) Peptide injections into the amygdala of conscious rats: effects on blood pressure, heart rate and plasma catecholamines. Regul Pept 21:95-106.

Burlitt E (1990) Expression of c-fos like protein as a marker of neuronal activity following noxious stimulation in the rat. J Comp Neurol 296:517-530.

Carter DA, Murphy D (1990) Regulation of c-fos and c-jun expression in the rat supraoptic nucleus. Cell Mol Neurobiol 10:435-445.

Ceccatelli S, Villar MJ, Goldstein M, Hökfelt T (1989) Expression of c-fos immunoreactivity in transmitter characterized neurons after stress. Proc Natl Acad Sci USA 86:9569-9573.

Cunningham ETJ, Sawchenko PE (1988) Anatomical specificity of noradrenergic inputs to the paraventricular and supraoptic nuclei of the rat hypothalamus. J Comp Neurol 274:60-76.

Cunningham ETJ, Bohn MC, Sawchenko PE (1990) Organization of adrenergic inputs to the paraventricular and supraoptic nuclei of the hypothalamus in the rat. J Comp Neurol 292:651-667.

Darlington DN, Ward DG (1985) Rostral pontine and caudal mesencephalic control of arterial pressure and iliac, celiac and renal vascular resistance. II. Separate control and topographic organization. Brain Res 361:301-308.

Dohanics J, Hoffman GE, Verbalis JG (1991) Hyponatremia-induced inhibition of magnocellular neurons causes stressor-selective impairment of stimulated adrenocorticotropin secretion in rats. Endocrinology 128:331-340.

Dun NJ, Dun SL, Chiaia NL (1993) Hemorrhage induces Fos immu- 
noreactivity in rat medullary catecholaminergic neurons. Brain Res 608:223-232.

Dunn FL, Brennan TJ, Nelson AE, Robertson GL (1973) The role of blood osmolality and volume in regulating vasopressin secretion in the rat. J Clin Invest 52:3212-3219.

Ebling FJP, Maywood ES, Stanley K, Humby T, Hancock DC, Waters $\mathrm{CM}$, Evan GI, Hastings $\mathrm{MH}$ (1991) The role of $\mathrm{N}$-methyl-aspartatetype glutamatergic neurotransmission in the photic induction of immediate-early gene expression in the suprachiasmatic nucleus of the syrian hamster. J Neuroendocrinol 3:641-652.

Eckland DJA, Todd K, Jessop DS, Biswas S, Lightman SL (1988) Differential effects of hypothalamic catecholamine depletion on the release of arginine vasopressin and CRF-41 into hypothalamo-hypophyseal portal blood. 90:292-298.

Fulwiler CE, Saper CB (1984) Subnuclear organization of the efferent connections of the parabrachial nucleus in the rat. Brain Res Rev $7: 229-259$.

Giovanelli L, Bloom FE (1992) C-fos protein expression in the rat subfornical organ following osmotic stimulation. Neurosci Lett 139 : $1-6$.

Greenberg ME, Ziff EB (1984) Stimulation of 3T3 cells induces transactivation of the c-fos protooncogene. Nature 312:432-437.

Guldenaar SEF, Noctor SC, McCabe JT (1992) Fos-like immunoreactivity in the brain of homozygous diabetes insipidus Brattleboro and normal Long-Evans rats. J Comp Neurol 322:439-448.

Harbuz MS, Chowdrey HS, Jessop DS, Biswas S, Lightman SL (1991) Role of catecholamines in mediating messenger RNA and hormonal responses to stress. Brain Res 551:52-57.

Hatton GI (1990) Emerging concepts of structure-function dynamics in adult brain: the hypothalamo-neurohypophysial system. Prog Neurobiol 34:437-504.

Herbert H, Moga MM, Saper CB (1990) Connections of the parabrachial nucleus with the nucleus of the solitary tract and the medullary reticular formation in the rat. J Comp Neurol 293:540-580.

Hoffman GE, Smith MS, Verbalis JG (1993) c-Fos and related immediate early gene products as markers of activity in neuroendocrine systems. Fronl Neuroendocrinol 14:173-213.

Honkaniemi, J (1993) Co-localization of peptide and tyrosine hydroxylase-like immunoreactivities with Fos-immunoreactive neurons in rat central amygdaloid nucleus after stress. Brain Res 598:107-113.

Hsu SM, Raine L, Fanger H (1981) Use of avidin-biotin-peroxidase complex $(\mathrm{ABC})$ in immunoperoxidase techniques: a comparison between $\mathrm{ABC}$ and unlabeled antibody (PAP) procedures. J Histochem Cytochem 29:577-580.

Hunt SP, Pini A, Evan G (1987) Induction of c-fos like protein in spinal cord neurons following sensory stimulation. Nature 328:632-634.

Imaki T, Shibasaki T, Hotta M, Demura H (1992) Early induction of c-fos precedes increased expression of corticotropin-releasing factor messenger ribonucleic acid in the paraventricular nucleus after immobilization stress. Endocrinology 131:240-246.

Irvine CHG, Alexander SL, Donald RA (1989) Effect of an osmotic stimulus to the secretion of arginine vasopressin and adrenocorticotropin in the horse. Endocrinology 124:3102-3108.

Jhamandas JH, Lind RW, Renaud LP (1989) Angiotensin II may mediate excitatory neurotransmission from the subfornical organ to the hypothalamic supraoptic nucleus: an anatomical and electrophysiological study in the rat. Brain Res 487:52-61.

Jhamandas JH, Harris KH, Petrov T, Krukoff TL (1992) Characterization of the parabrachial nucleus input to the hypothalamic paraventricular nucleus of the rat. J Neuroendocrinol 4:461-471.

Johnson AK, Gross PM (1993) Sensory circumventricular organs and brain homeostatic pathways. FASEB J 7:678-686.

Kainu T, Honkaniemi J, Gustafsson J-Å, Reichardt L, Pelto-Huikko M (1993) Co-localization of peptide-like immunoreactivities with glucocorticoid receptor- and Fos-like immunoreactivities in the rat parabrachial nucleus. Brain Res 615:245-251.

Kalia M, Fuxe K (1985) Rat medulla oblongata. I. Cytoarchitectonic considerations. J Comp Neurol 233:285-307.

Kalia M, Mesulam MM (1980) Brain stem projections of sensory and motor components of the vagus complex in the cat. II. Laryngeal, tracheobronchial, pulmonary, cardiac, and gastrointestinal branches. J Comp Neurol 193:467-508.

Kalia M, Fuxe K, Goldstein M (1985a) Rat medulla oblongata. II. Dopaminergic, noradrenergic (A1 and A2) and adrenergic neurons, nerve fihers, and presumptive terminal processes. J Comp Neurol 233:308-332.

Kalia M, Fuxe K, Goldstein M (1985b) Rat medulla oblongata. III. Adrenergic ( $\mathrm{C} 1$ and $\mathrm{C} 2)$ neurons, nerve fibers and presumptive terminal processes. J Comp Neurol 233:333-349.

Knigge U, Warberg J (1991) The role of histamine in the neuroendocrine regulation of pituitary hormone secretion. Acta Endocrinol 124: $609-619$.

Kovács KJ, Sawchenko PE (1993) Mediation of osmoregulatory influences on neuroendocrine corticotropin-releasing factor expression by the ventral lamina terminalis. Proc Natl Acad Sci USA 90:76817685.

Larsen PJ, Hay-Schmidt A, Mikkelsen JD (1994) Efferent connections from the lateral preoptic and lateral hypothalamic regions to the hypothalamic paraventricular nucleus in the rat. I Comp Neurol 342: 299-319.

Leng G, Dyball REJ, Russell JA (1988) Neurophysiology of body fluid homeostasis. Comp Biochem Physiol 90:781-788.

Leng G, Blackburn RE, Dyball REJ, Russell JA (1989) Role of anterior peri-third ventricular structures in the regulation of supraoptic neuronal activity and neurohypophysial hormone secretion in the rat. $\mathbf{J}$ Neuroendocrinol 1:35-46.

Leng G, Dyball REJ, Luckman S (1992) Mechanisms of vasopressin secretion. Horm Res 37:33-38.

Leslie RA, Gwyn DG, Hopkins DA (1982) The central distribution of the cervical vagus and gastric afferent and efferent projections in the rat. Brain Res Bull 8:37-43.

Li Z, Ferguson AV (1993) Subfornical organ efferents to paraventricular nucleus utilize angiotensin as a neurotransmitter. Am J Physiol 265:R302-R309.

Lightman SL, Young WS III (1988) Corticotrophin-releasing factor, vasopressin and pro-opiomelanocortin mRNA responses to stress and opiates in the rat. J Physiol (Lond) 403:511-523.

Lightman SL, Young WS III (1989) Influence of steroids on the hypothalamic corticotropin-releasing factor and preproenkephalin mRNA responses to stress. Proc Natl Acad Sci USA 86:4306-4310.

Lind RW, Swanson LW (1984) Evidence for corticotropin-releasing factor and leu-enkephalin in the neural projection from the lateral parabrachial nucleus to the median preoptic nucleus: a retrograde transport, immunocytochemical double labeling study in the rat. Brain Res 321:217-224.

Lind RW, Ohman LE, Lansing MB, Johnson AK (1983) Transection of subfornical organ neural connections diminishes the pressor response to intravenously infused angiotensin II. Brain Res 275:361364.

Mangiapane ML, Simpson JB (1980) Subfornical lesions reduce the pressor effect of systemic angiotensin II. Neuroendocrinology 31: 380-384.

Mikkelsen JD, Larsen PJ, Sørensen GG, Woldbye D, Bolwig TG, Hastings MH, Ebling FJP (1994) A dual-immunocytochemical method to localize c-fos protein in specific neurons based on their content of neuropeptides and connectivity. Histochemistry 101:245-253.

Miselis RR (1981) The efferent projections of the subfornical organ of the rat: a circumventricular organ with a neural network subserving water balance. Brain Res 230:1-23.

Morgan JI, Curran T (1991) Stimulus-transcription coupling in the nervous system: involvement of the inducible proto-oncogenes fos and jun. Annu Rev Neurosei 14:421-451.

Nguyen KQ, Sills MA, Jacobwitz DM (1986) Cardiovascular effects produced by microinjections of calcitonin gene-related peptide into the rat central amygdaloid nucleus. Peptides 7:337-339.

Norgren R (1985) Taste and the autonomic nervous system. Chem Senses 10:143-161.

Paxinos G, Watson C (1986) The rat brain in stereotaxic coordinates, 2d ed. Sydney: Academic

Plotsky PM (1987) Regulation of hypophysiotropic factors mediating ACTH secretion. In: The hypothalamic-pituitary axis revisited (Ganong W, Dallman M, Roberst J, eds), pp 205-217. New York: New York Academy of Sciences.

Plotsky PM, Cunningham ET, Widmaier EP (1989) Catecholaminergic modulation of corticotropin-releasing factor and adrenocorticotropin secretion. Endocrine Rev 10:437-458.

Ramsay DJ, Trasher TN, Keil LC (1983) The organum vasculosum laminae terminalis: a critical area for osmoreception. Prog Brain Res 60:91-94. 
Riche D, De Pommery J, Menetrey D (1990) Neuropeptides and catecholamines in efferent projections of the nuclei of the solitary tract in the rat. J Comp Neurol 293:399-424.

Ruggiero DA, Pickel VM, Milner TA, Anwar M, Otake K, Mtui EP, Park D (1994) Viscerosensory processing in nucleus tractus solitarii: structural and neurochemical substrates. In: Nucleus of the solitary tract (Barraco RIA, ed), pp 3-34. Boca Raton, FL: CRC.

Sagar SM, Sharp FR, Curran T (1988) Expression of c-fos protein in brain: metabolic mapping at the cellular level. Science 240:13281331.

Saper CB, Loewy AD (1980) Efferent connections of the parabrachial nucleus in the rat. Brain Res 197:291-317.

Saphier D (1991) Paraventricular nucleus magnocellular responses following electrical stimulation of the midbrain dorsal raphe. Exp Brain Res 85:359-363.

Sawchenko PE, Swanson LW (1982a) Immunohistochemical identification of neurons in the paraventricular nucleus of the hypothalamus that project to the medulla or to the spinal cord in the rat. J Comp Neurol 205:260-272.

Sawchenko PE, Swanson LW (1982b) The organization of noradrenergic pathways from the from the brain stem to the paraventricular and supraoptic nuclei in the rat. Brain Res Rev 4:275-325.

Sawchenko PE, Swanson LW, Steinbush HWM, Verhofstad AAJ (1983) The distribution and cells of origin of serotonergic inputs to the paraventricular nuclei of the rat. Brain Res 277:355-360.

Sawchenko PE, Swanson LW, Vale WW (1984) Co-expression of corticotropin-releasing factor and vasopressin immunoreactivities in parvocellular neurosecretory neurons in the hypothalamus of adrenalectomized rats. Proc Natl Acad Sci USA 81:1883-1887.

Sawchenko PE, Swanson LW, Grzanna R, Howe PRC, Bloom SR, Polak JM (1985) Colocalization of neuropeptide $Y$ immunoreactivity in brainstem catecholaminergic neurons that project to the paraventricular nucleus of the hypothalamus. J Comp Neurol 241:138-153.

Sawchenko PE, Imaki T, Vale W (1992) Co-localization of neuroactive substances in the endocrine hypothalamus In: Functional anatomy of the neuroendocrine hypothalamus (Chadwick DJ, Marsh J, ed). Chichester: Wiley.

Sharp FR, Sagar SM, Hicks K, Lowenstein D, Hisanaga K (1991) C-fos mRNA, FOS and Fos-related antigen induction by hypertonic saline and stress. J Neurosci 11:2321-2331.

Sharpiro RE, Miselis RR (1985) The central organization of the vagus nerve innervating the stomach of the rat. J Comp Neurol 328:178488.

Sheng M, Greenberg ME (1990) The regulation and function of c-fos and other immediate early genes in the nervous system. Neuron $4: 477-485$

Shimada S, Shiosaka S, Emson PC, Hillyard CJ, Girgis S, MacIntyre L, Tohyama M (1985) Calcitonin gene-related peptidergic projection from the parabrachial area to the forebrain and diencephalon in the rat: an immunohistochemical analysis. Neuroscience 16:607-616.

Shinohara Y, Yamano M, Matsuzaki T, 'lohyama M (1988) Evidences for the coexistence of substance P, neurotensin and calcitonin generelated peptide in single neurons of the external subdivision of the lateral parabrachial nucleus of the rat. Brain Res Bull 20:257-260.

Swanson LW (1987) The hypothalamus. In: Handbook of chemical neuroanatomy (Björklund A, Hökfelt T, Swanson LW, eds), pp 1124. Amsterdam: Elsevier.

Swanson LW, Sawchenko PE (1983) Hypothalamic integration: organization of the paraventricular and supraoptic nuclei. Annu Rev Neurosci 6:269-324.

Swanson LW, Sawchenko PE (1986) Regulation of multiple peptides in CRF parvocellular neurosecretory neurons: implications for the stress response. Prog Brain Res 68:169-190.

Whitehead MC (1990) Subdivisions and neuron types of the nucleus of the solitary tract that project to the parabrachial nucleus in the hamster.

Yamada J, Kitamura T (1992) Spinal cord cells innervating the bilateral parabrachial nuclei in the rat. A retrograde fluorescent double-labcling study. Neurosci Res 15:273-280.

Zardetto-Smith AM, Gray TS (1990) Organization of catecholaminergic efferents from the nucleus of the solitary tract to the rat amygdala. Brain Res Bull 25:875-887. 